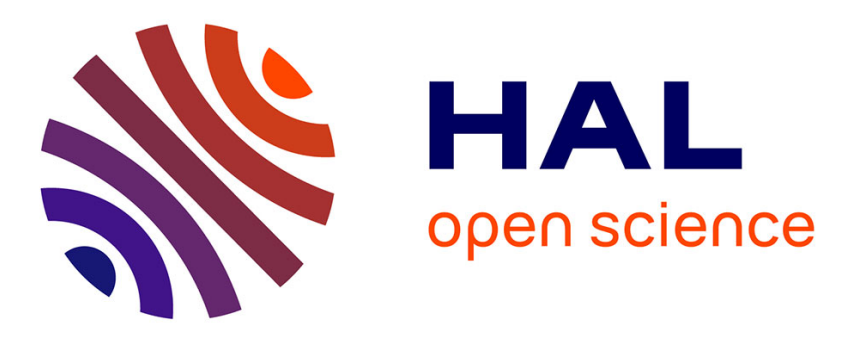

\title{
Heat transfer of water-based carbon nanotube nanofluids in the shell and tube cooling heat exchangers of the gasoline product of the residue fluid catalytic cracking unit
}

S. Masoud Hosseini, Mohammad Reza Safaei, Patrice Estellé, S. Hadi Jafarnia

\section{To cite this version:}

S. Masoud Hosseini, Mohammad Reza Safaei, Patrice Estellé, S. Hadi Jafarnia. Heat transfer of water-based carbon nanotube nanofluids in the shell and tube cooling heat exchangers of the gasoline product of the residue fluid catalytic cracking unit. Journal of Thermal Analysis and Calorimetry, 2020, 140 (1), pp.351-362. 10.1007/s10973-019-08813-5 . hal-02294361

HAL Id: hal-02294361

https://hal-univ-rennes1.archives-ouvertes.fr/hal-02294361

Submitted on 1 Oct 2019

HAL is a multi-disciplinary open access archive for the deposit and dissemination of scientific research documents, whether they are published or not. The documents may come from teaching and research institutions in France or abroad, or from public or private research centers.
L'archive ouverte pluridisciplinaire HAL, est destinée au dépôt et à la diffusion de documents scientifiques de niveau recherche, publiés ou non, émanant des établissements d'enseignement et de recherche français ou étrangers, des laboratoires publics ou privés. 


\title{
Heat transfer of water based carbon nanotube nanofluids in the shell and tube cooling heat exchangers of the gasoline product of the Residue Fluid Catalytic Cracking unit
}

\author{
S. Masoud Hosseini a , Mohammad Reza Safaei ${ }^{\text {b,c }}$, Patrice Estellé ${ }^{\text {d,* }}$, S. Hadi Jafarnia ${ }^{\text {a }}$ \\ ${ }^{a}$ Chemical and Process Engineering Department of the RFCC Unit, Arak Oil Refining Company, Arak, Iran \\ ${ }^{\mathrm{b}}$ Division of Computational Physics, Institute for Computational Science, Ton Duc Thang University, Ho Chi Minh City, Vietnam \\ ${ }^{\mathrm{c}}$ Faculty of Electrical and Electronics Engineering, Ton Duc Thang University, Ho Chi Minh City, Vietnam \\ ${ }^{\mathrm{d}}$ Univ Rennes, LGCGM, EA3913, F-35000 Rennes, France \\ * Corresponding author: Patrice.estelle@univ-rennes1.fr
}

\begin{abstract}
In this study, a series of low concentration carbon nanotubes (CNT) water-based nanofluids $(0.0055$, $0.055,0.111$ and 0.278 vol\%) were used as coolants in a shell and tube cooler of the Residue Fluid Catalytic Cracking (RFCC) gasoline product to analyze their effects on heat performance of the heat exchanger. The coolants and gasoline flow in tube side and shell side, respectively. This work was performed through simulating the heat exchanger by ASPEN HTFS+ 7.3 software. The performance of the nanofluids to heat transfer was analyzed in comparison with cooling water. Results illustrated that $0.055 \% \mathrm{CNT}$ concentration could enhance heat transfer properties of the heat exchanger such as Nusselt number, total heat transfer coefficient and heat transfer rate more than other concentrations. Therefore, the lowest temperature of outlet shell side fluid was also observed at this concentration. Moreover, increment of mass flow rates of both the tube side and shell side fluids caused enhancement of the heat transfer, especially with 0.055 vol\% CNT. Although there is an optimum concentration among the studied CNT volume fractions, all nanofluids exhibit better thermal performance of the heat exchanger than cooling water, whereas pressure drop increases with CNT loading.
\end{abstract}

Keywords: Tube and shell heat exchanger, Carbon nanotube water- based nanofluids, Concentration, Mass flow rate, Thermal performance 


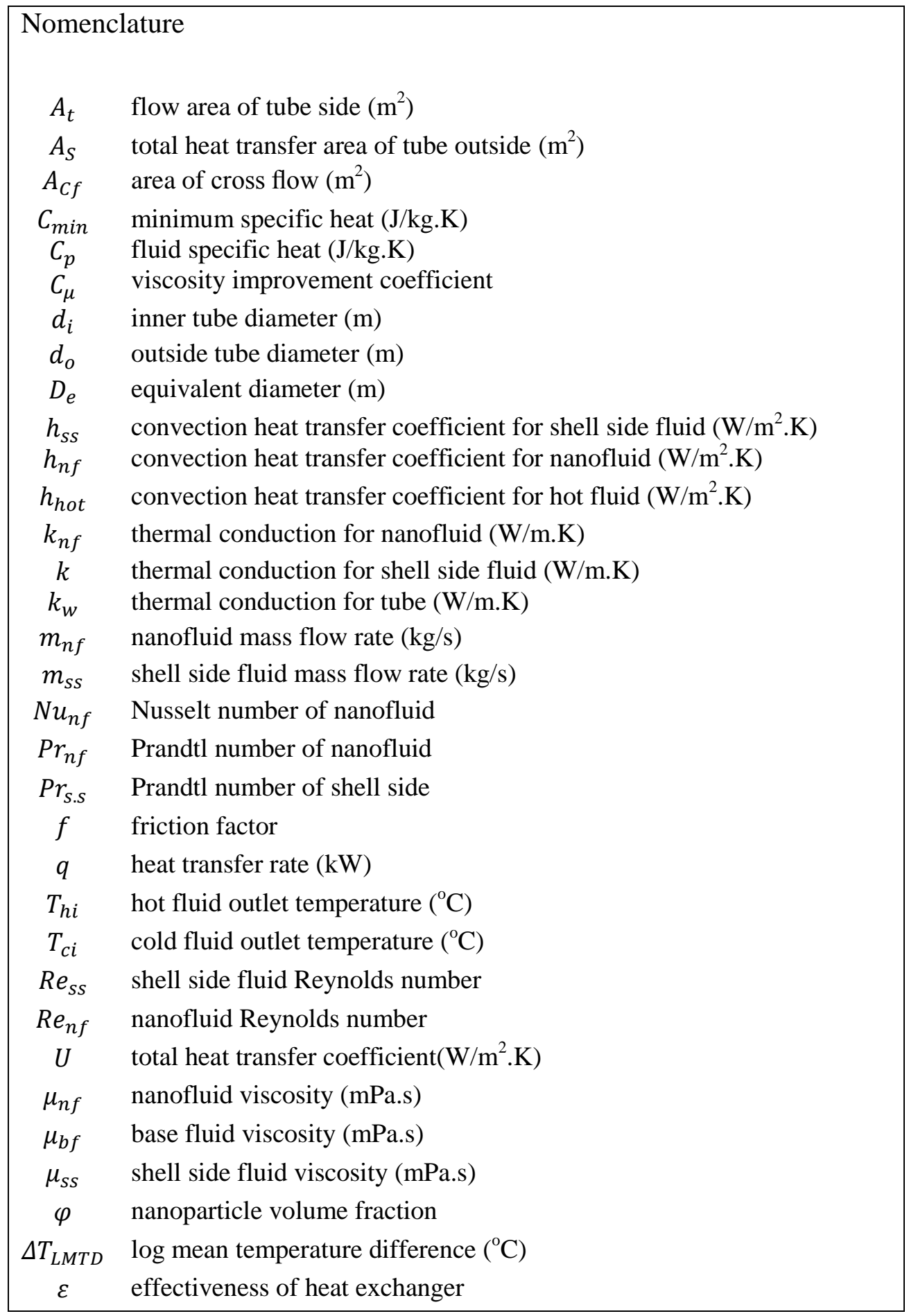

\section{Introduction}

Nanofluids are engineered colloidal suspensions of nanoparticles $<100 \mathrm{~nm}$ in a base fluid, which have recently been proposed as new generation of heat transfer fluids. Various nanoparticles have been selected to produce nanofluids, including metals [1, 2], metal oxides $[3,4]$ and nonmetals $[5,6]$. These suspensions exhibit noticeably higher thermal conductivity 
than the pure liquid [7] which could improve heat transfer in heat exchangers [8,9] since low thermal conductivity of the process fluids like water, ethylene glycol and industrial oils $[1,2$, 10,11] prevents high effectiveness of heat exchangers through making their heat transfer capability limited. Therefore, in most applications in which cooling or heating processes are performed by conventional fluids, nanofluids could be used rather than common single phase fluids. For instance, nanofluids can be used in refrigerators, solar heaters, heating and cooling of buildings, radiators of cars, condensing and evaporating systems, oil recovery, medicine drug delivery and any type of liquid based heat exchangers [12-17, 18-20]

Heat exchangers are important devices in chemical processes and industries in the field of energy and heat transfer. One of heat exchangers types is shell and tube one which is used in oil and gas industries, for example.

In recent years, the use of nanofluids in the heat exchangers, like shell and tube type, has thoroughly been recognized as a promising possibility in order to enhance heat transfer performance and save energy in various processes [21].

Barzegarian et al. [22] used $\mathrm{Al}_{2} \mathrm{O}_{3}$-water nanofluids in a shell and tube heat exchanger and evaluated the effect of friction factor, Reynolds number and nanoparticles volume fraction on the heat performance. This work was performed under laminar flow condition. They found that the total heat transfer coefficient and thermal performance factor could be improved by increasing $\mathrm{Re}$ and nanoparticles volume fraction. For example, with $0.3 \%$ vol. in $\mathrm{Al}_{2} \mathrm{O}_{3}$ nanoparticles, the total heat transfer coefficient and thermal performance factors are increased by $29.8 \%$ and $18.9 \%$ respectively with a weak increase in the pressure drop.

Likewise, similar nanofluids were investigated by Shahrul et al. [23] in a tube and shell heat exchanger. They studied the effect of mass flow rate of both the shell and tube sides. The heat exchanger performance was analyzed and the results were compared with water. These experiments demonstrated that the total heat transfer coefficient increased up to $26 \%$ in comparison with water and greatest performance was observed at 7 LPM flow rate.

Hosseini et al. [24] studied CNT-water nanofluid with low volume fractions. The performance of an industrial heat exchanger was simulated by heat exchanger design, rating and simulation software in laminar flow regime. They concluded that with increase of CNT concentration, heat transfer properties would be increased so that the total heat coefficient is $14.5 \%$ higher and heat rate reached $10.3 \%$ for the highest volume concentration. Furthermore, increasing CNT concentration caused reduction of temperature of the outlet of the shell side fluid compared with water. It was demonstrated that increasing mass flow rate 
could increase heat transfer. Increase in pressure drop and pumping power was reported to be small and negligible.

Al-Abdali et al. [25] also conducted an experimental investigation on water based $\mathrm{Al}_{2} \mathrm{O}_{3}$ nanofluid to determine the evolution of the friction factor and Nusselt number in a tube and shell heat exchanger. The tubes were finned and without fin. The Reynolds number were changed from 3,000 to 10,500 , also the nanofluid volume concentration was $0.1 \%, 0.2 \%$, and $0.3 \%$. It was observed that Nusselt number and friction factor increased with nanofluid concentration. Increasing Re (increasing turbulence) led to higher Nusselt number. At highest nanofluid concentration $(0.3 \%)$, the Nusselt number increased by $25.6 \%$ for tube without fin. For finned tube, Nusselt number increased by $11.8 \%$ for highest Reynolds number $(\mathrm{Re}=$ 10500) and highest nanofluid concentration of $0.3 \%$.

Aghabozorg et al. [26] used nanofluid made of distilled water and $\mathrm{Fe}_{2} \mathrm{O}_{3}-\mathrm{CNT}$ magnetic nanoparticle in a horizontally positioned tube and shell heat exchanger. They carried out test under various flow conditions (laminar, transient and turbulent flows) and three different heat fluxes. The results showed that increasing $\phi$ and $\mathrm{T}$ results in higher convection heat transfer coefficient. The heat transfer coefficient of the nanofluid was higher than base fluid. At $\phi$ $=0.1 \%$, heat transfer increased by $13.54 \%$ and $27.69 \%$ for laminar and turbulent flows. For $\phi$ $=0.2 \%$, the heat transfer coefficient increased by $34.02 \%$ and $37.50 \%$ in comparison with distilled water for laminar and turbulent flows condition respectively.

Many works performed on heat transfer of nanofluids in various types of heat exchangers are experimental. Although experimental studies are worthwhile approaches to research, they go with some disadvantages such as determining difficultly contribution of physical phenomena to the system as well as the possible high expense of experiments that are obstacles for doing experimental studies because it can require a large amount of sample or specific technical developments. Thus, modeling and simulation are going great on their ways to becoming beneficial and wonder alternatives rather than experiments [27] as not only make lower costs but also can give highly detailed data and results on the system studied [27]. However, this requires using appropriate models for thermophysical properties or reliable experimental data.

In the current study, simulation of the Residue Fluid Catalytic Cracking unit (RFCC) gasoline product shell and tube cooler was carried out by using CNT-water nanofluids as coolant in low nanoparticle volume fractions. The simulation was performed considering real experimental data for nanofluids as done in previous works with different configurations such as square cavity [28], pipe [29] and microchannel heat sink [30]. The heat transfer 
performance of the RFCC was analyzed considering the influence of nanofluid concentrations and fluid mass flow rate.

\section{2- Problem definition}

One of oil refining units (in Arak Petroleum Refinery, Iran) is called RFCC (residue fluidized catalytic cracking). There is a debutanizer tower in this unit where gasoline and LPG, produced through RFCC process, are separated from each other in this tower as LPG is up flow and gasoline is bottom one. Outlet gasoline product from debutanizer column bottom, after passing through six air coolers, flows through the shell sides of two shell and tube heat exchangers in order to be more cooled by cooling water flows in tubes. Figure 1 illustrates this real shell and tube heat exchangers that is investigated in this study.

A branch of the cooled gasoline is utilized as the absorber fluid in a LPG absorption column (is called primary absorber). In this tower, LPG of the process gas which contents fuel gas (Methane and Ethane) as well is absorbed by the mentioned cooled gasoline as absorber fluid in order to be separated from the fuel gas. Therefore, the gasoline temperature is a very significant item since, generally, temperature is a vital factor in absorption process and this justifies the use of the mentioned heat exchangers for regulating (decreasing) the temperature of the gasoline.

During the warm seasons of year, the air coolers could not be entirely capable to work on total duty. Likewise, temperature of the cooling water supply flowing in the tubes increases because of high ambient temperature and being the utility power plant unable to supply the cooling water with the regulated temperature (usually $25{ }^{\circ} \mathrm{C}$ ). Therefore, cooling performance efficiency in the shell and tube heat exchanger decreases. Consequently, outlet temperature of shell side gasoline rises, leading to lower absorption efficiency in the primary absorber column, causing loss of LPG through top flow. Enhancing the thermal properties of the heat transfer fluids is one of the methods for solving this problem. With this goal, the use of water based nanofluid containing carbon nanotubes in the heat exchanger has been analyzed numerically. 


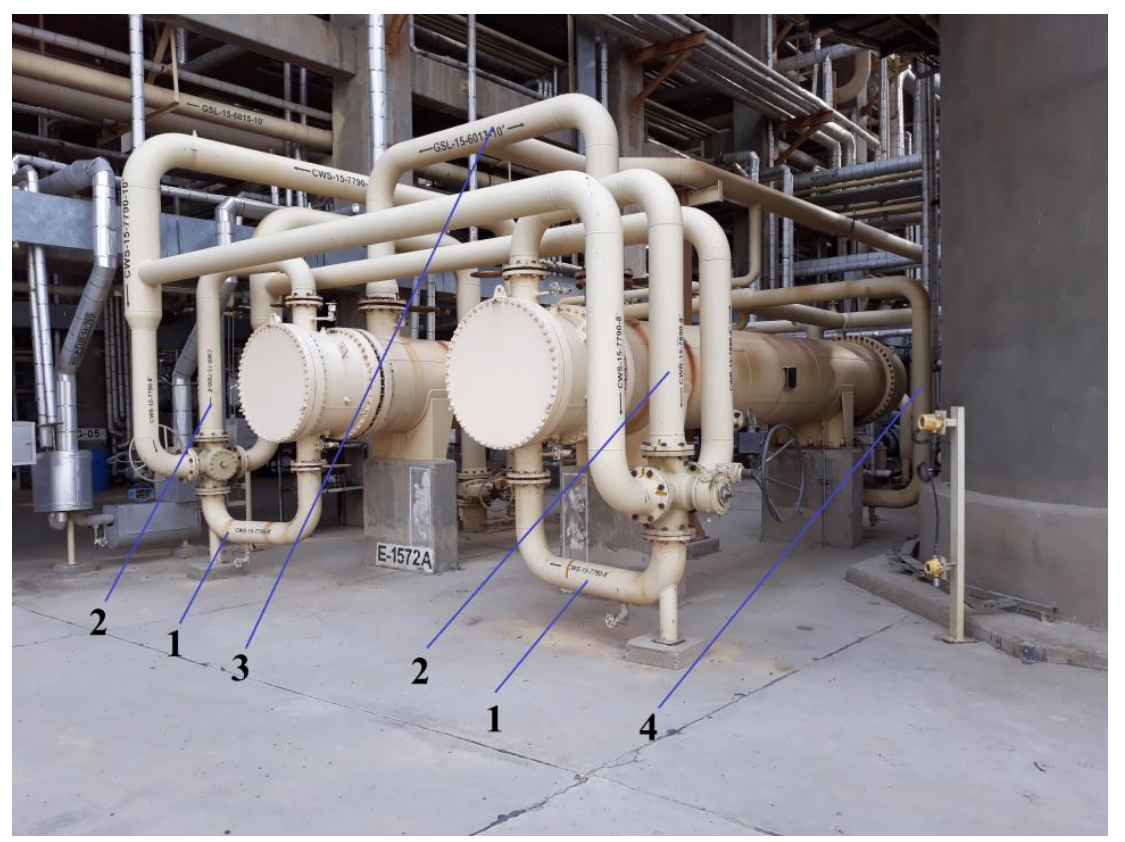

Fig.1. Real shell and tube cooling heat exchangers of the RFCC gasoline product that have been modelized. (1) Inlet cooling water to tubes, (2) Outlet cooling water from tubes, (3) Inlet gasoline product to shell, (4) Outlet gasoline product from shell

\section{Modelling}

The calculations for heat exchangers design and simulation are hugely difficult and complicated. For instance, to design a heat exchanger, many initial guesses must be considered which make calculations really irritating and boring as well as they increase probability of error in results. But, by using the software, all these calculations are performed by computer with noticeably faster pace just through applying the operational condition and the properties of working fluids as well as much more precise results would be available.

ASPEN HTFS+ 7.3 is useful software to simulate, design and evaluate the performance of the various types of heat exchangers such as shell and tube, plate, kettle and air cooler heat exchanger. This software is more comprehensive in data bank and the applications and features than the others like B-JAC software. HTFS+ has four calculation modes such as Design, Checking, Simulation and Maximum Fouling.

Among the mentioned calculation modes, simulation mode is here considered to simulate the shell and tube heat exchanger described in Fig.1. Within this mode, the heat exchanger specifications, the composition and operational/process condition of the shell side and tube side fluids and the cooling fluid thermophysical properties are entered into the software as inlet data. Then, after running the software, it makes the outlet fluids process condition and 
heat transfer rate available. Water based CNT nanofluids were introduced as cooling fluids. It is mentionable that thermophysical properties of the shell side fluid (gasoline) are calculated by the software through the composition and process condition. For thermophysical properties of the nanofluid as tube side cooling fluid, the data from Halelfadl et al. [31] were used in order to supply input data for the simulation software. Volume fractions of the nanofluids were $0.0055 \%, 0.055 \%, 0.111 \%$ and $0.278 \%$. More details about nanofluids characterization and properties evaluation can be found elsewhere [31]. Figure 2 expresses the influence of temperature and CNT loading effects on the thermophysical properties of presently used CNT nanofluids [31]. Because of turbulent flow involved within the tube of the heat exchanger, viscosity data of the CNT-water nanofluids used and reported in Figure 2 are for high shear rate. All other data necessary to the simulation process are gathered in Tables 1 and 2. Table 1 presents gasoline composition. Likewise, Table 2 contains information about heat exchanger geometry. Figures 3(a) [32] and 3 (b) (given from the software) also demonstrate schematically some geometry specifications as well as the flow parameters.

At first, the simulation was performed with water as cooling fluid to ensure validity of the results. After that, nanofluid simulations were carried out. 

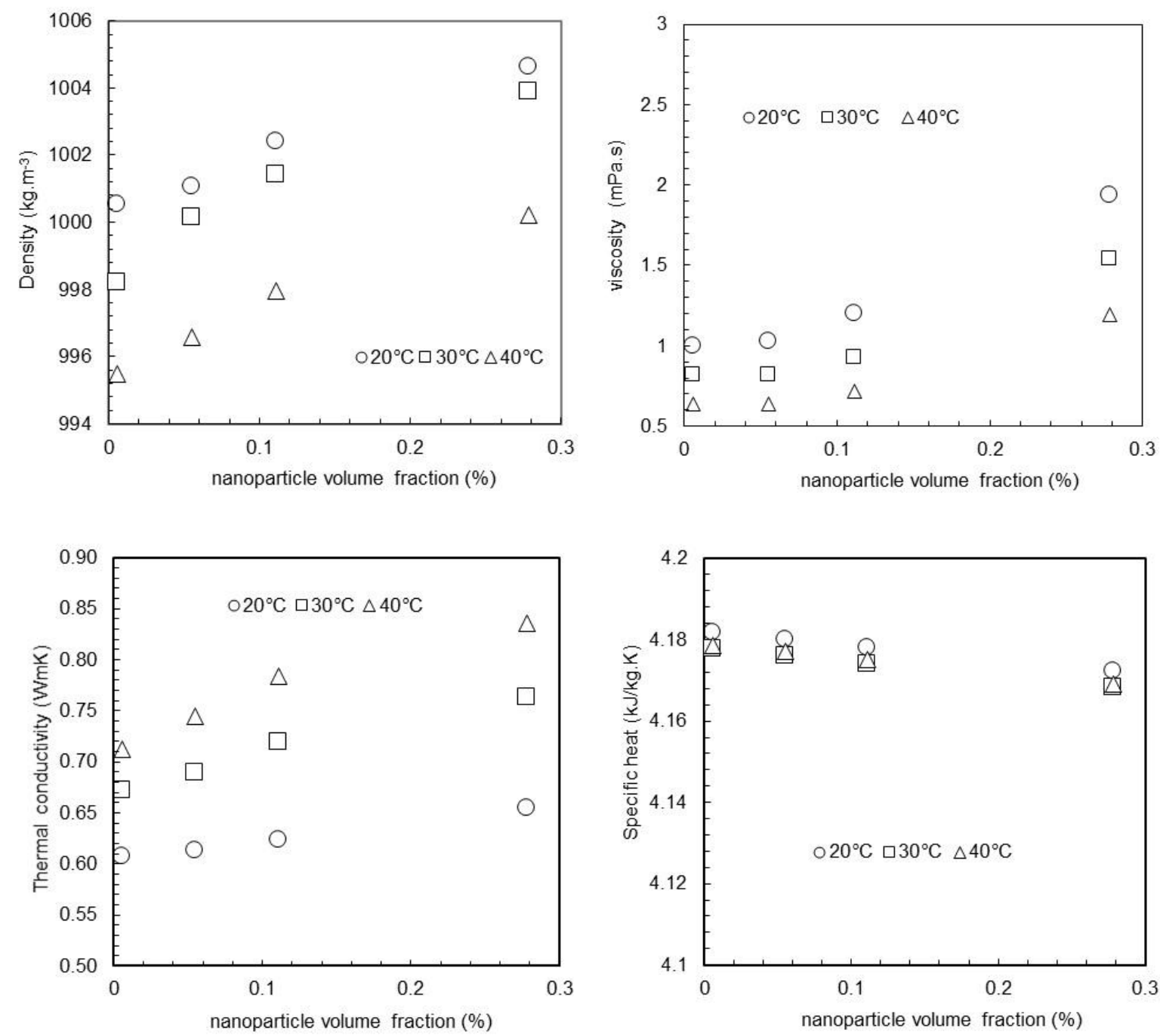

Fig. 2. Effects of temperature and CNT volume fraction on the thermophysical properties of nanofluids from [31] 
Table1. Composition of gasoline (shell side fluid)

\begin{tabular}{|c|c|c|c|}
\hline $\begin{array}{c}\text { Component } \\
\text { name }\end{array}$ & $\mathbf{k m o l} / \mathbf{h r}$ & $\begin{array}{c}\text { Component } \\
\text { name }\end{array}$ & $\mathbf{k m o l} / \mathbf{h r}$ \\
\hline $\mathrm{H}_{2} \mathrm{O}$ & $1.7 \mathrm{E}-16$ & $=\mathrm{N} 1 \mathrm{C} 4$ & 2.87 \\
\hline $\mathrm{CO}$ & $3.3 \mathrm{E}-18$ & $=\mathrm{T} 2 \mathrm{C} 4$ & 10.51 \\
\hline $\mathrm{CO}_{2}$ & $5.3 \mathrm{E}-19$ & $=\mathrm{C} 2 \mathrm{C} 4$ & 16.80 \\
\hline $\mathrm{H}_{2} \mathrm{~S}$ & $1 . \mathrm{E}-10$ & IC4 & 2.64 \\
\hline$=\mathrm{C} 2$ & $2.5 \mathrm{E}-18$ & NC4 & 10.45 \\
\hline $\mathrm{C} 2$ & $1 . \mathrm{E}-14$ & $=1 \mathrm{C} 5$ & 669.97 \\
\hline$=\mathrm{C} 3$ & 0.00022 & IC5 & 357.84 \\
\hline $\mathrm{C} 3$ & 0.00067 & NC5 & 63.50 \\
\hline$=\mathrm{IC} 4$ & 2.65 & $\mathrm{C} 6+$ (Product) & 3458.56 \\
\hline
\end{tabular}

Table 2. Specification of the heat exchanger as well as operational condition of the fluids in shell Side (gasoline) and tube side (the coolants)

\begin{tabular}{|c|c|c|c|}
\hline Parameter & Amount/type & Parameter & Amount/type \\
\hline $\begin{array}{l}\text { Shell inner diameter } \\
(\mathrm{mm})\end{array}$ & 950 & Baffle type & $\begin{array}{c}\text { Single } \\
\text { segmental }\end{array}$ \\
\hline $\begin{array}{l}\text { Shell outer diameter } \\
(\mathrm{mm})\end{array}$ & 974 & Baffle spacing (center-center) (mm) & 310 \\
\hline Tube number & 868 & Baffle cut $\%$ & 27 \\
\hline Tube passes per shell & 4 & $\begin{array}{l}\text { Mass flow rate of fluid in shell side } \\
\text { (gasoline) }(\mathrm{kg} / \mathrm{s})\end{array}$ & 124.7631 \\
\hline Tube length (mm) & 6100 & $\begin{array}{l}\text { Mass flow rate of tube side fluid (cooling } \\
\text { water and the nanofluid) }(\mathrm{kg} / \mathrm{s})\end{array}$ & 81.7394 \\
\hline $\begin{array}{l}\text { outer diameter of } \\
\text { Tube (mm) }\end{array}$ & 19.05 & Shell side fluid Inlet temperature $\left({ }^{0} \mathrm{C}\right)$ & 55 \\
\hline $\begin{array}{l}\text { Thickness of Tube } \\
(\mathrm{mm})\end{array}$ & 1.65 & Tube side fluid Inlet temperature $\left({ }^{0} \mathrm{C}\right)$ & 29 \\
\hline Tube pitch (mm) & 27.4 & Shell side fluid Inlet pressure (bar) & 10.3 \\
\hline Tube pattern & $\begin{array}{c}\text { 45-Rotated } \\
\text { sqr. }\end{array}$ & Tube side fluid Inlet pressure (bar) & 3.9 \\
\hline
\end{tabular}




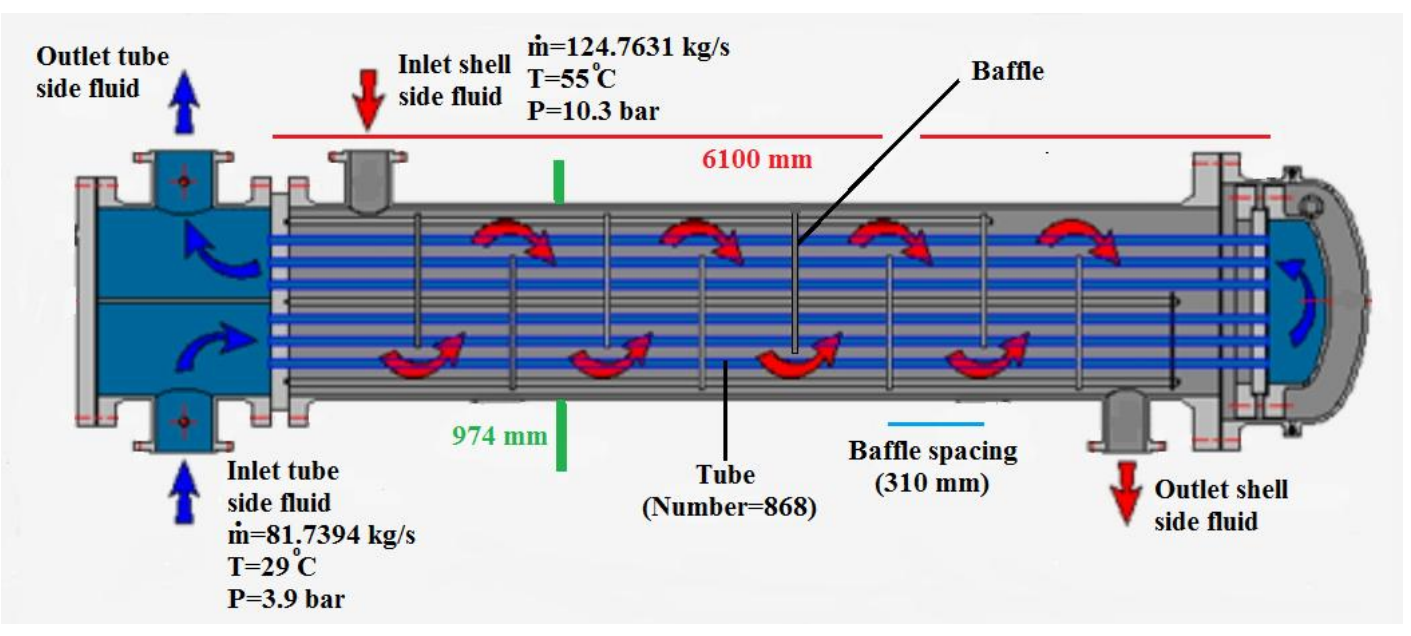

Fig. 3a. Schematic figure of the heat exchanger [29]

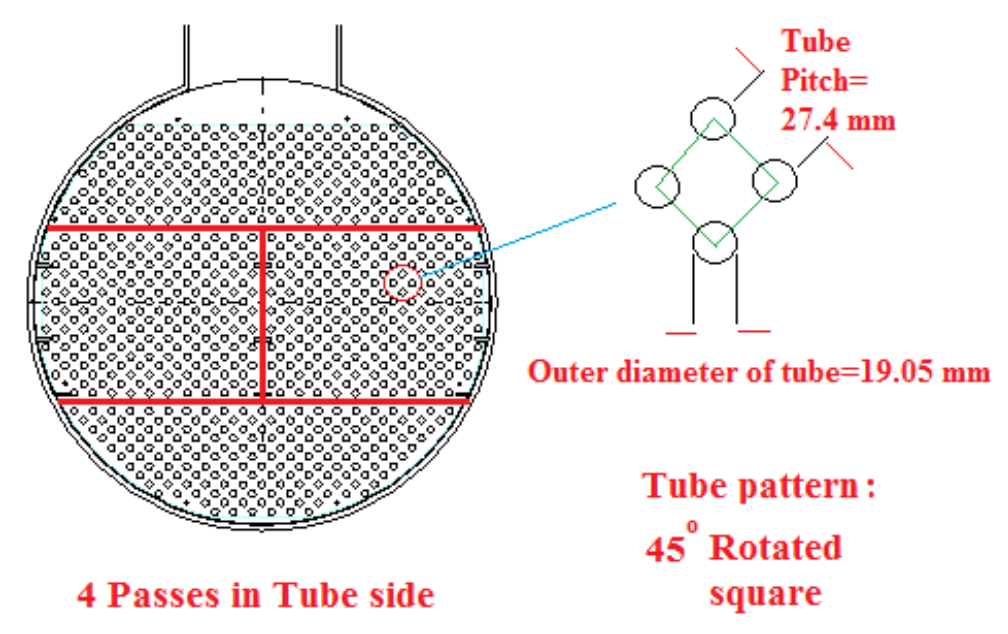

Fig. 3b. Tube sheet and tube pattern of the heat exchanger schematically

\section{Results and discussion}

4.1. Influence of the nanoparticle concentration on thermal performance of tube and shell sides at constant mass flow rates

Figure 4 shows the nanofluid Reynolds number $\operatorname{Re}_{\mathrm{nf}}$, evaluated from equation (1), in function CNT concentration at constant $\dot{\mathrm{m}}=81.74 \mathrm{~kg} / \mathrm{s}$ in tube side. It is observed that $\mathrm{Re}_{\mathrm{nf}}$ decreases by increasing CNT concentration due to the increase of nanofluid viscosity with the content in nanotubes. Range values of $\mathrm{Re}_{\mathrm{nf}}$ indicates that the flow is under turbulent regime as expected.

$$
R e_{n f}=\frac{m_{n f} d}{A_{t} \mu_{n f}}
$$




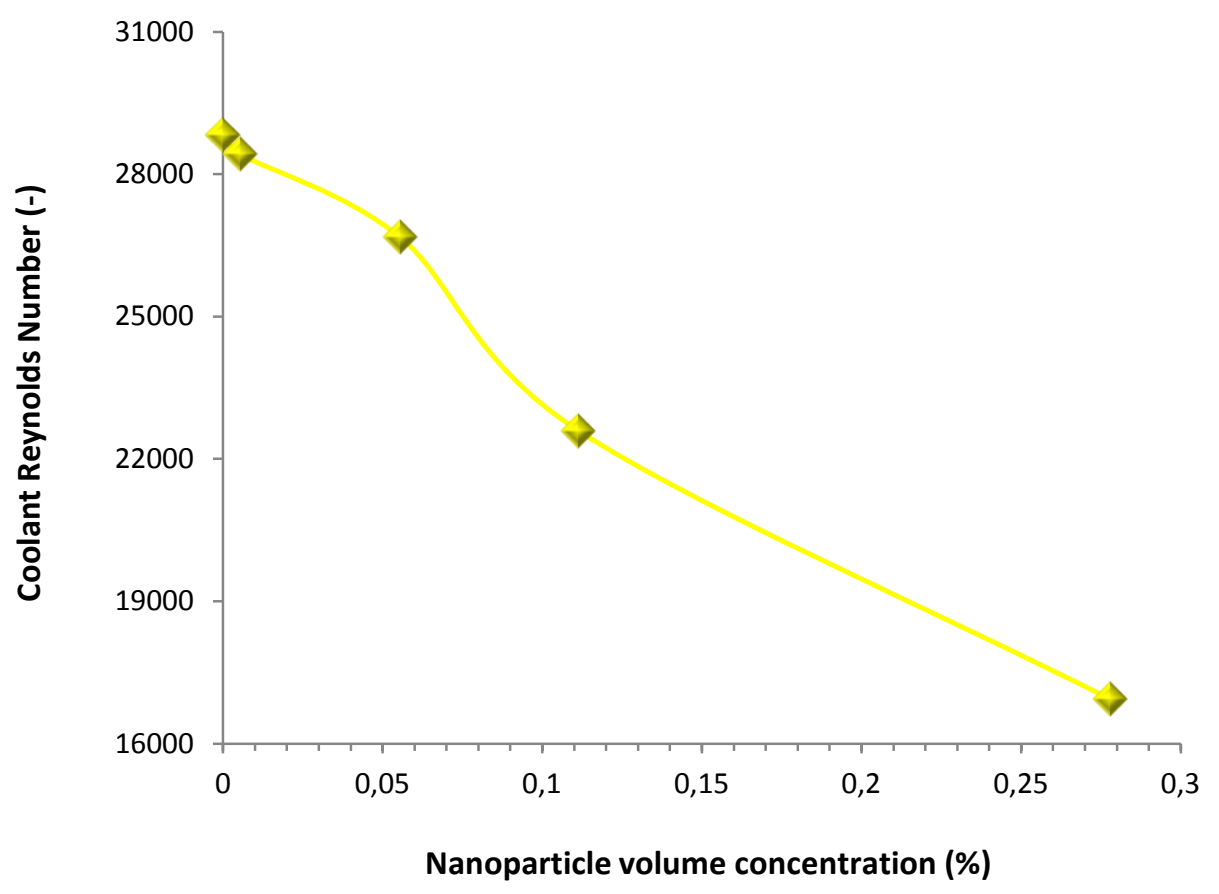

Fig. 4. Re of coolant as a function of CNT loading

Figure 5 shows variations of Prandtl number, calculated from equation (2), with CNT volume concentration. First, Prandtl number decreases for volume fraction $0.0055 \%$ and then increases for higher concentrations. Regarding Prandtl number equation (Eq. 2), the effect of $\mathrm{k}$ and $\mathrm{c}_{\mathrm{p}}$ is higher than $\mu$ for $\phi=0.0055 \%$ because $\mu$ is close to the value of water. But increasing $\phi$ intensifies the effect of $\mu$ on Pr resulting in higher Pr value.

$\operatorname{Pr}=\frac{C_{p} \mu}{k}$ 


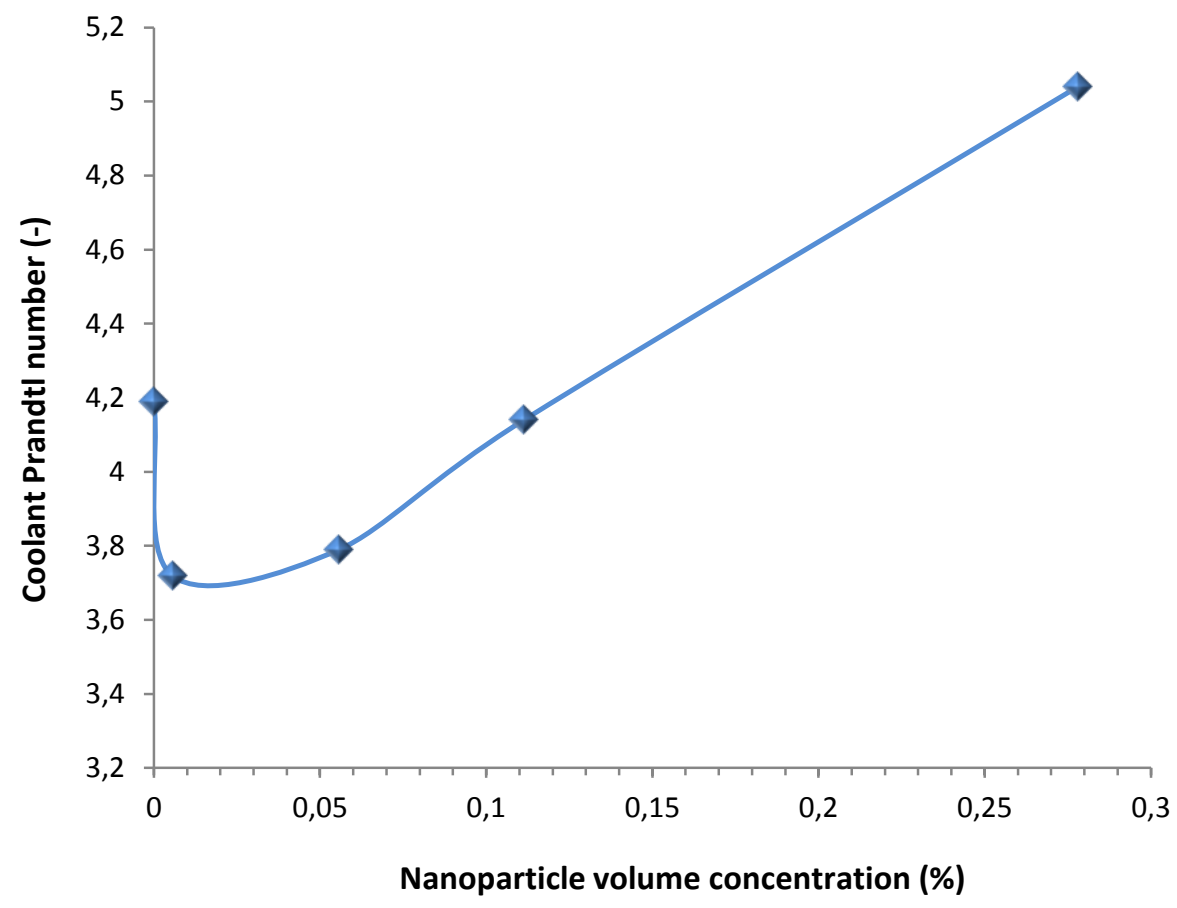

Fig. 5. Coolant Prandtl number as a function of CNT loading

Figure 6 represents the friction factor evolution vs. CNT volume concentration. Friction factor for water and nanofluid flow were calculated with the Gnielinski (Eq. 3) [33] and Duangthongsuk and Wongwises (Eq. 4) [34] equations, respectively. This figure shows that the increase of friction factor with nanotubes concentration.

$$
\begin{aligned}
& f=[1.58 \operatorname{Ln} R e-3.82]^{-2} \\
& f=0.961 R e^{-0.375} \varphi^{0.052}
\end{aligned}
$$




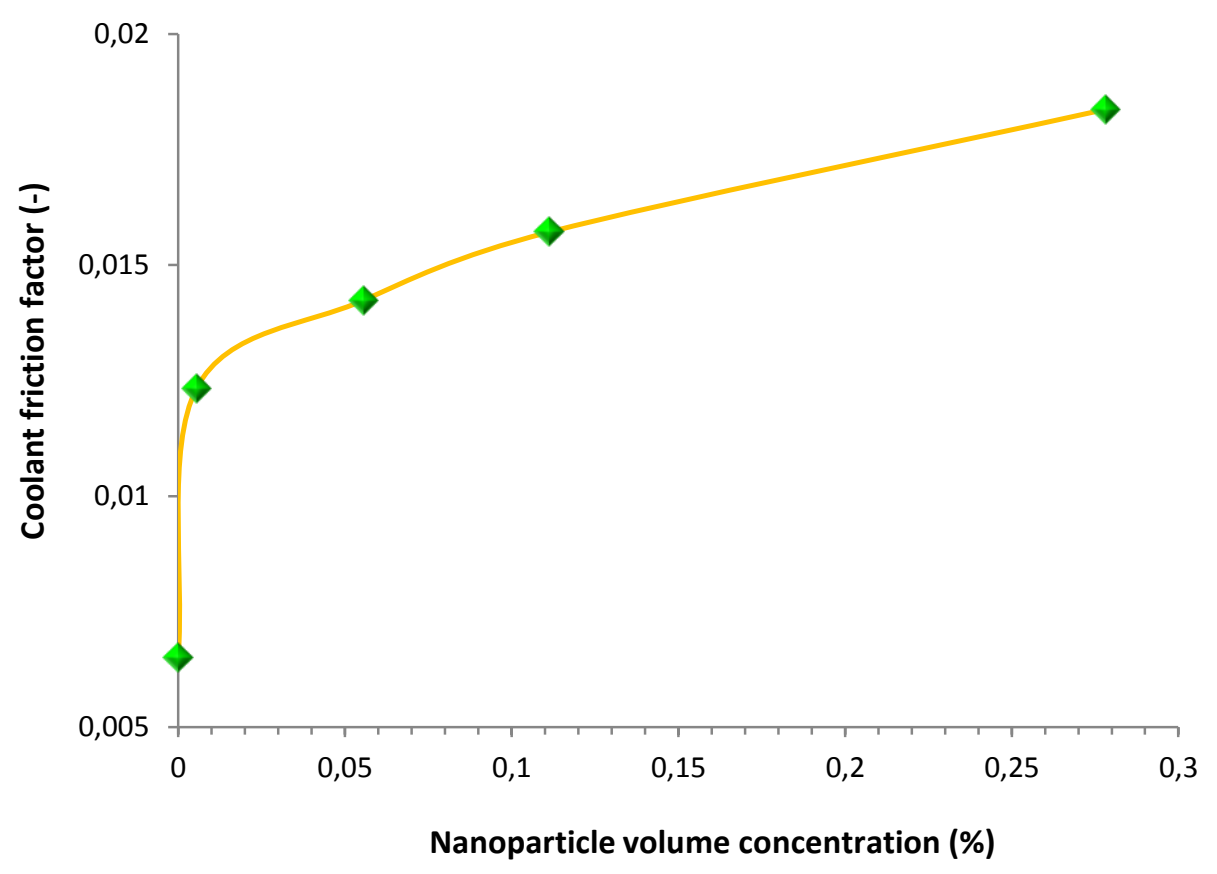

Fig. 6. Coolant friction factor as a function of CNT loading

Figure 7 shows Nusselt number trend with CNT volume fraction, calculated through Gnielinski relationship [33] expressed by equation 5 for water and various volume concentration of the CNT-water nanofluid by using previous equations and results.

$$
N u=\frac{(0.125 f)(R e-1000) P r}{1+12.7(0.125 f)^{0.5}\left(\operatorname{Pr}^{\frac{2}{3}}-1\right)}
$$

Increase of Nusselt numbers for $0.0055 \%, 0.055 \%, 0.111 \%$ and $0.278 \%$ volume fractions are about $30 \%, 32 \%, 20 \%$ and $2.3 \%$, respectively, related to the water. Therefore, increment of the Nusselt number for $0.055 \%$ volume fraction is highest related to the others. 


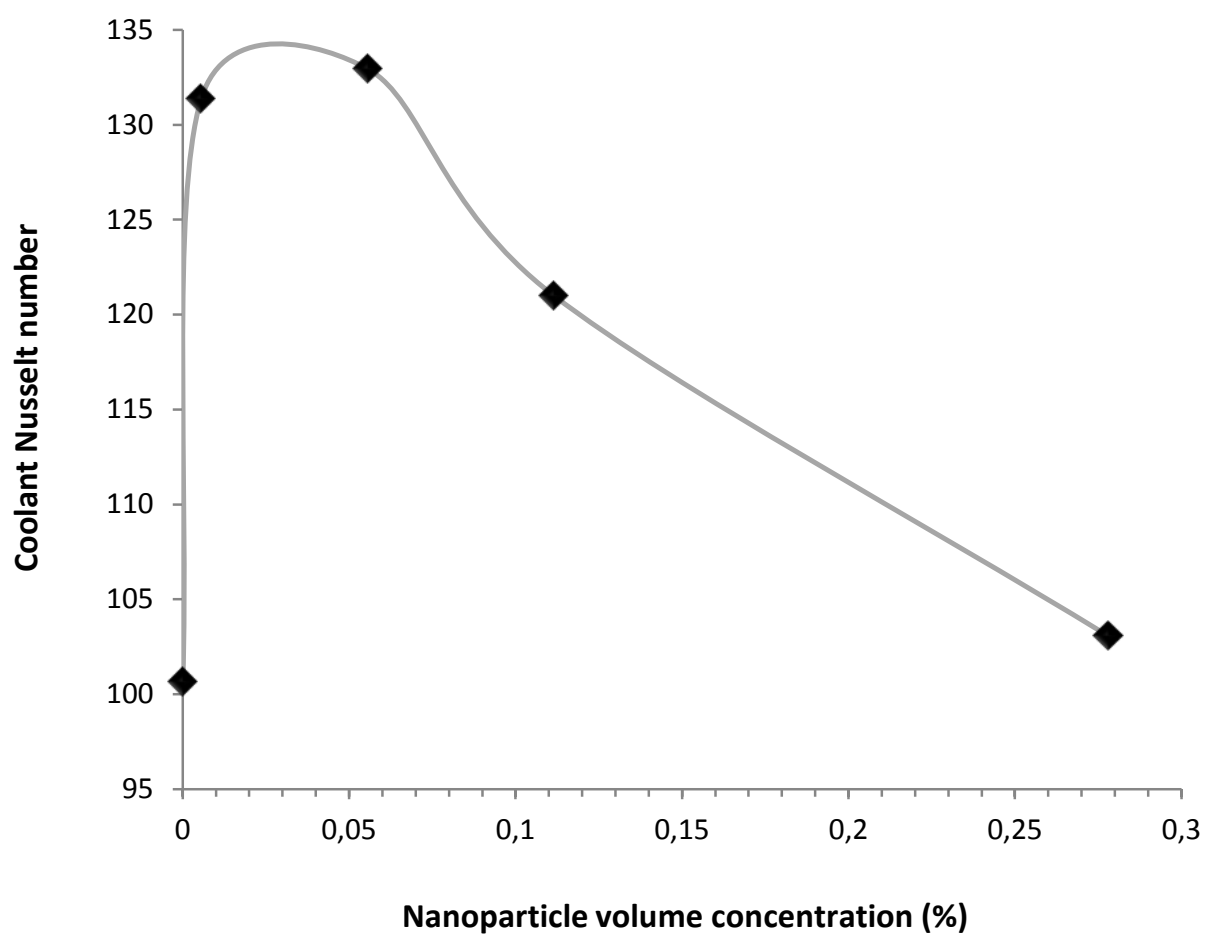

Fig. 7. Coolant Nusselt number as a function of CNT loading

Figure 8 shows the total heat transfer coefficient vs. $\phi$. According to Eq. 6, Nusselt number and fluid thermal conductivity are proportional to the convection heat transfer coefficient. Increasing the Nusselt number of the fluids to $0.055 \%$ CNT volume concentration and increasing thermal conductivity through increasing $\phi$ results in higher total heat transfer coefficient. $0.055 \% \mathrm{CNT}$ volume concentration possesses maximum total heat transfer coefficient related to others about $650.7 \mathrm{~W} / \mathrm{m}^{2} \mathrm{~K}$. For higher concentrations, the total heat transfer coefficient decreases by reducing Nusselt number (Eq. 7). 


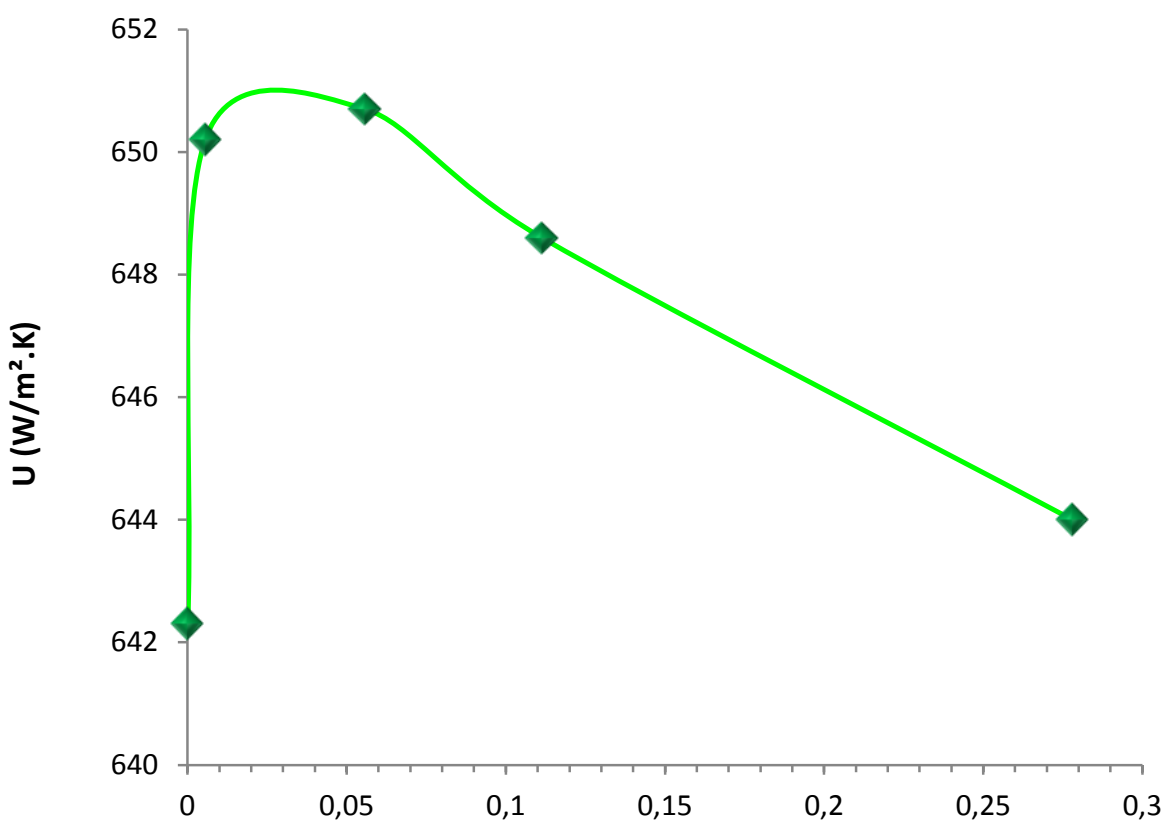

Nanoparticle volume concentration (\%)

Fig. 8. Total heat transfer coefficient as a function of CNT loading

Heat transfer rate is proportional to total heat transfer coefficient (Eq. 8). Figure 9 shows heat transfer vs CNT concentrations. A maximum heat transfer of about $4133 \mathrm{~kW}$ occurs at $\phi=$ 0.055 vol. \% since the total heat transfer coefficient is maximum at this point. The total heat transfer coefficient and heat transfer rate for all the CNT concentrations are higher than for water.

$h_{n f}=\frac{N u_{n f} \cdot K_{n f}}{d_{i}}$

$\frac{1}{U}=\frac{1}{h_{h o t}}+\frac{d_{o} \ln \left(\frac{d_{o}}{d_{i}}\right)}{2 k_{w}}+\frac{1}{h_{n f}} \frac{d_{o}}{d_{i}}$

$q=U A_{s} \Delta T_{L M T D}$ 


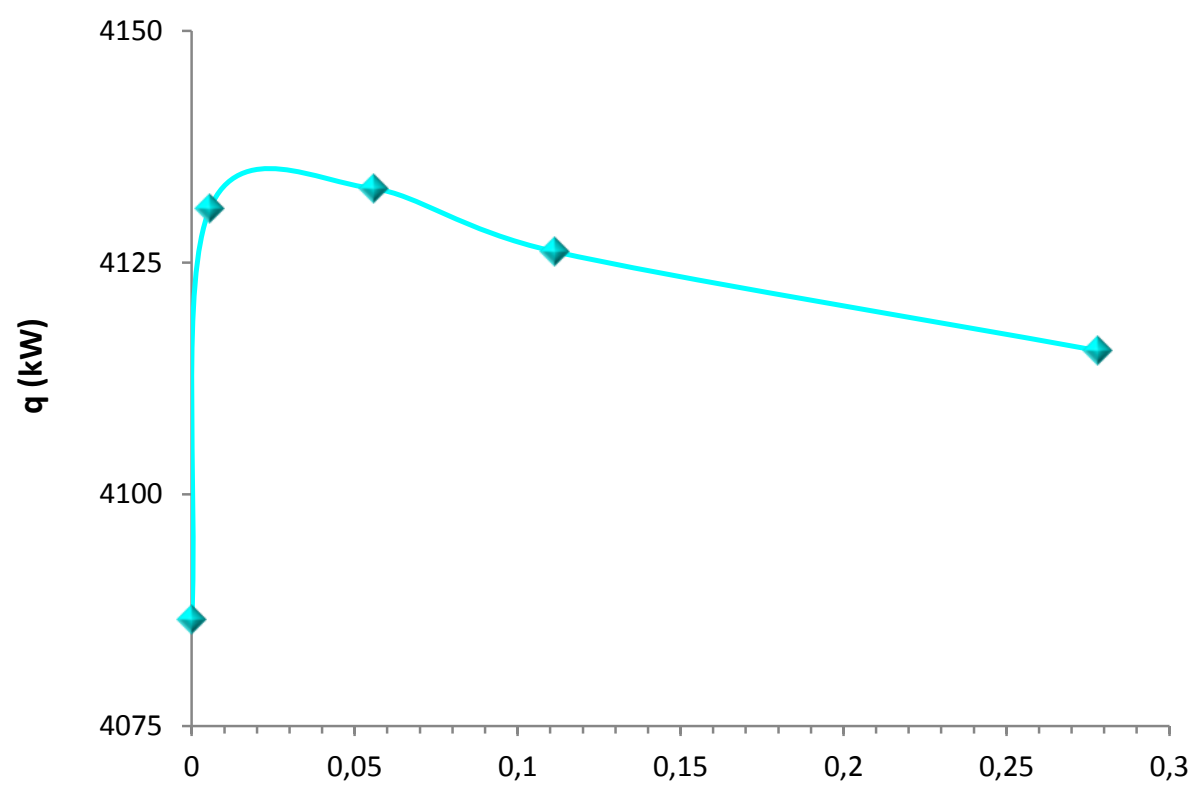

Nanoparticle volume concentration (\%)

Fig. 9. Heat transfer rate as a function of CNT loading

Since maximum heat transfer rate is obtained for 0.055 vol. \% CNT nanofluids, the minimum temperature of shell side fluid outlet occurs at $\phi=0.055$ as shown in Figure 10.

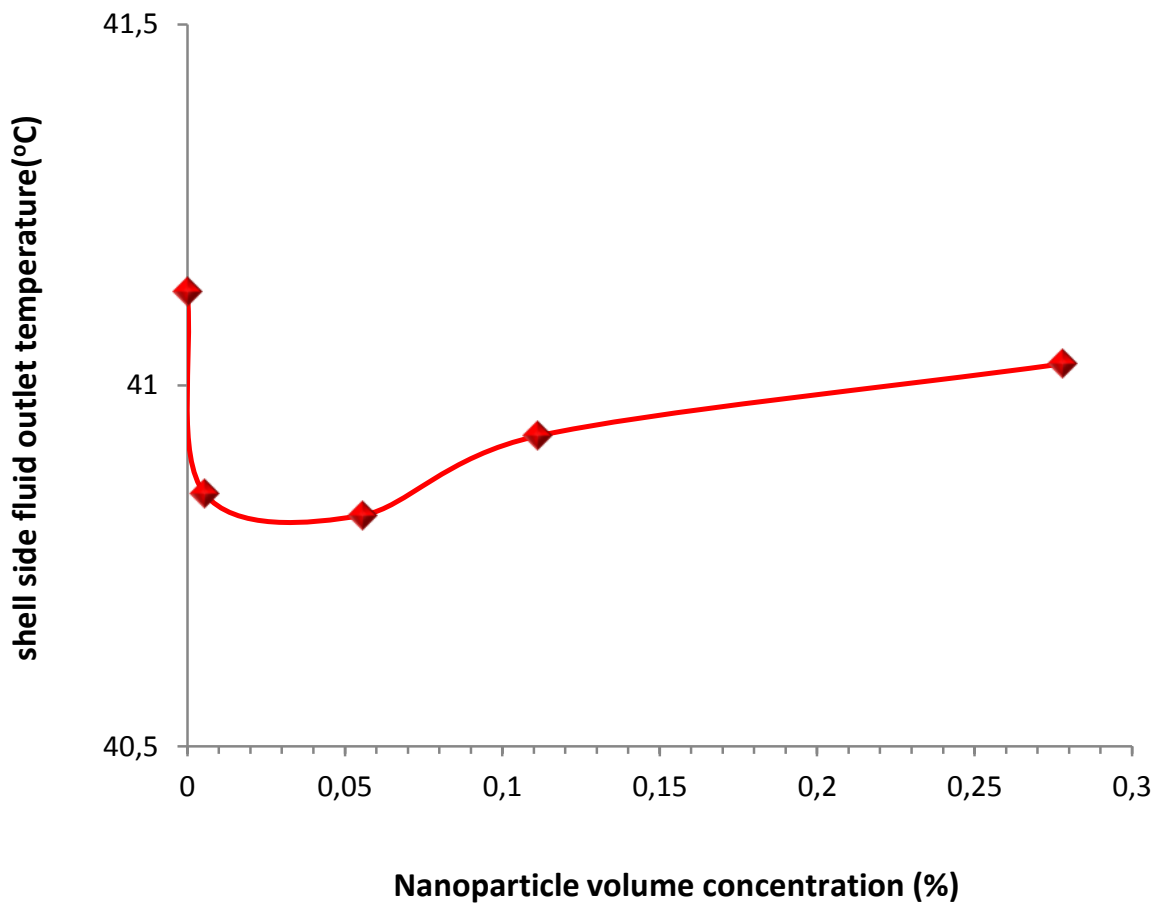

Fig. 10. Outlet temperature of shell side fluid versus CNT loading 
Figure 11 illustrates that pressure drop in tube side, provided by the software, increases with CNT concentration, which is directly linked to the increase in viscosity with higher $\phi$, and the effect is more prominent at higher $\phi$ values which have higher pressure loss as well.

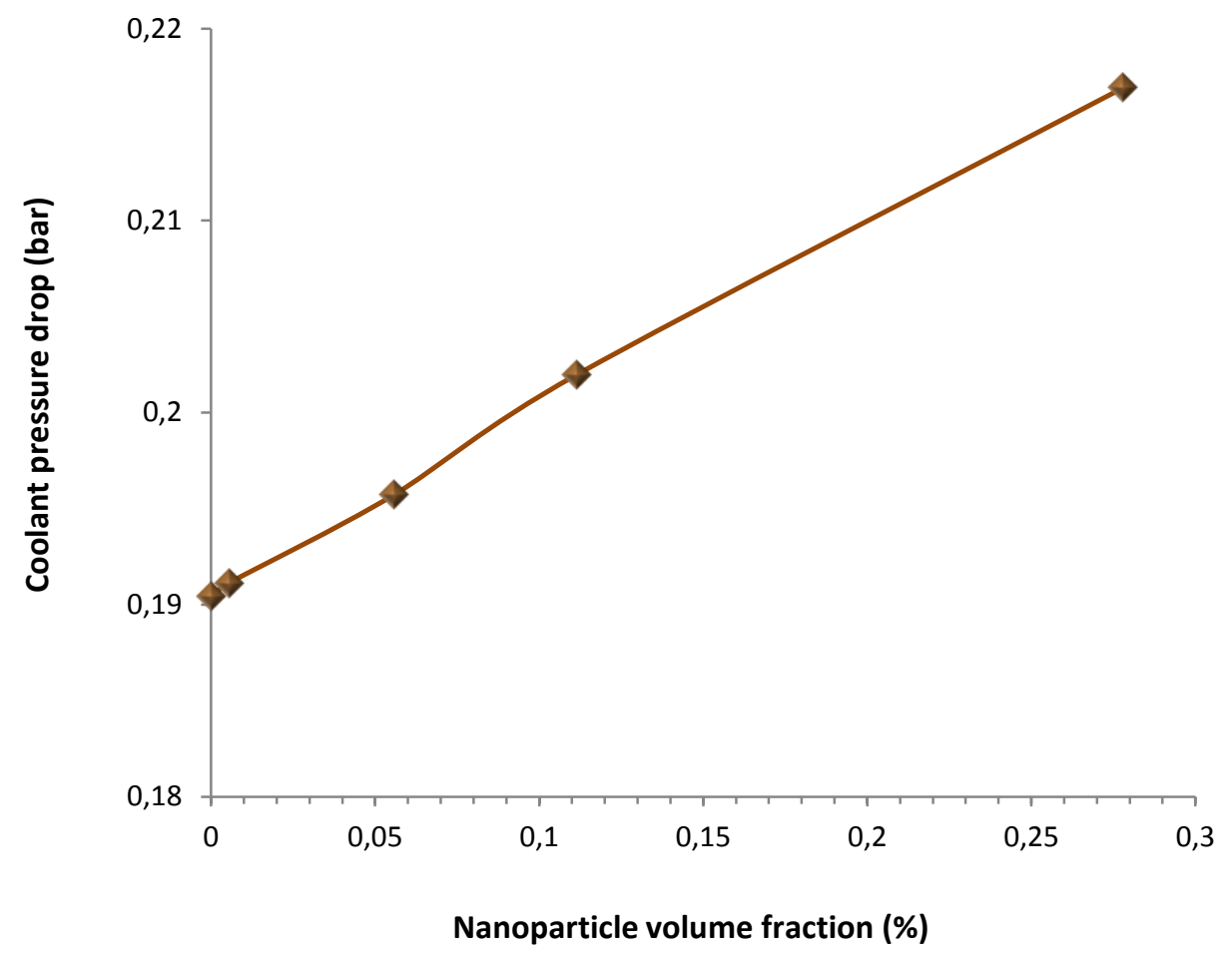

Fig. 11. Coolant pressure drop as a function of CNT loading

\subsection{Influence of CNT nanofluid mass flow rate on thermal performance}

According to Eq. (1), the coolant Reynolds's number is function of the mass flow rate at a constant $\phi$. Hence, when the nanofluid mass flow rate is increased, its Reynolds's number rises, too. This explanation has been portrayed in Figure 12. With increment of coolant mass flow rate, Prandtl number also increases for a constant $\phi$ (Figure 13). 


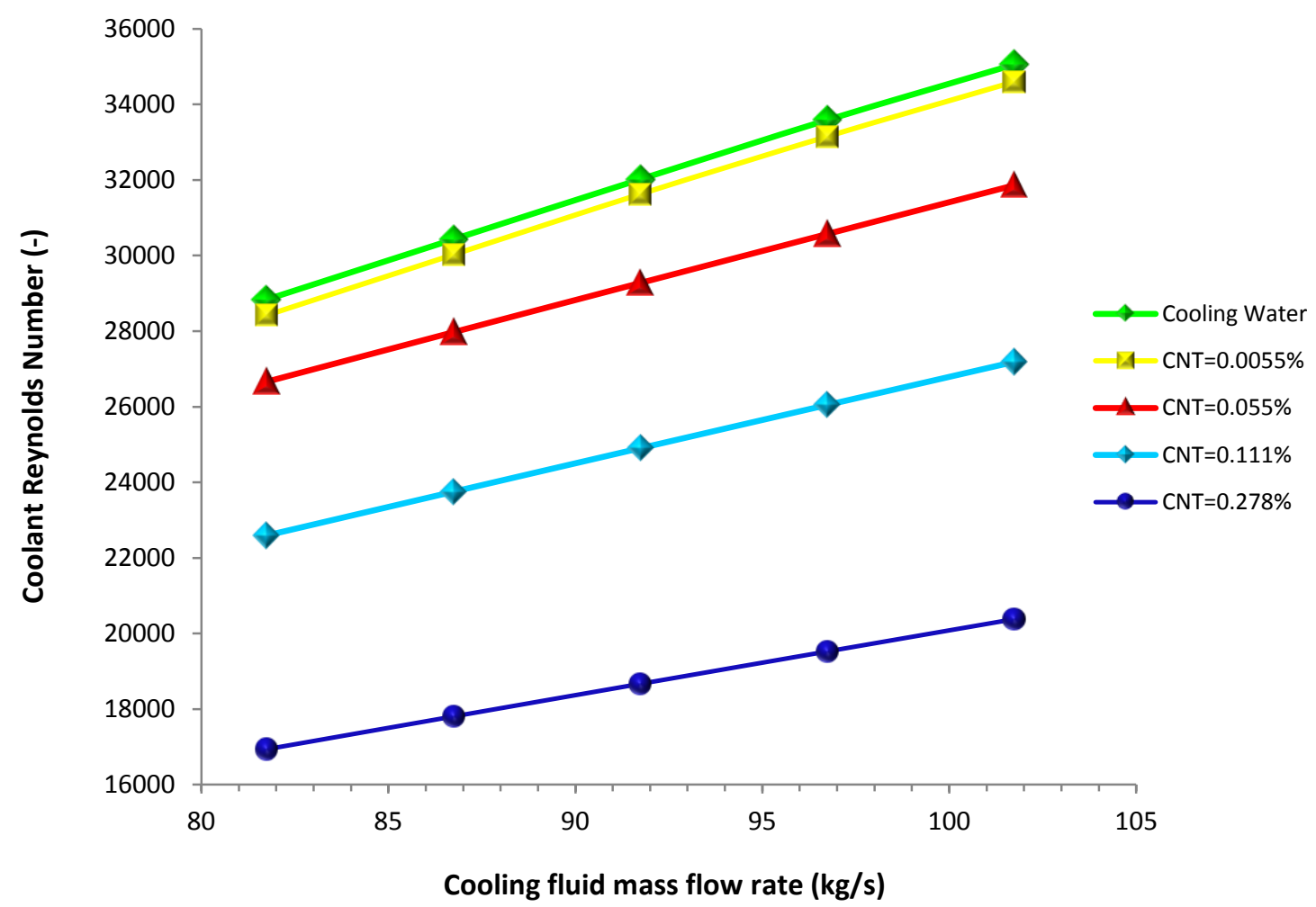

Fig. 12. Effect of $m_{n f}$ on Reynolds number

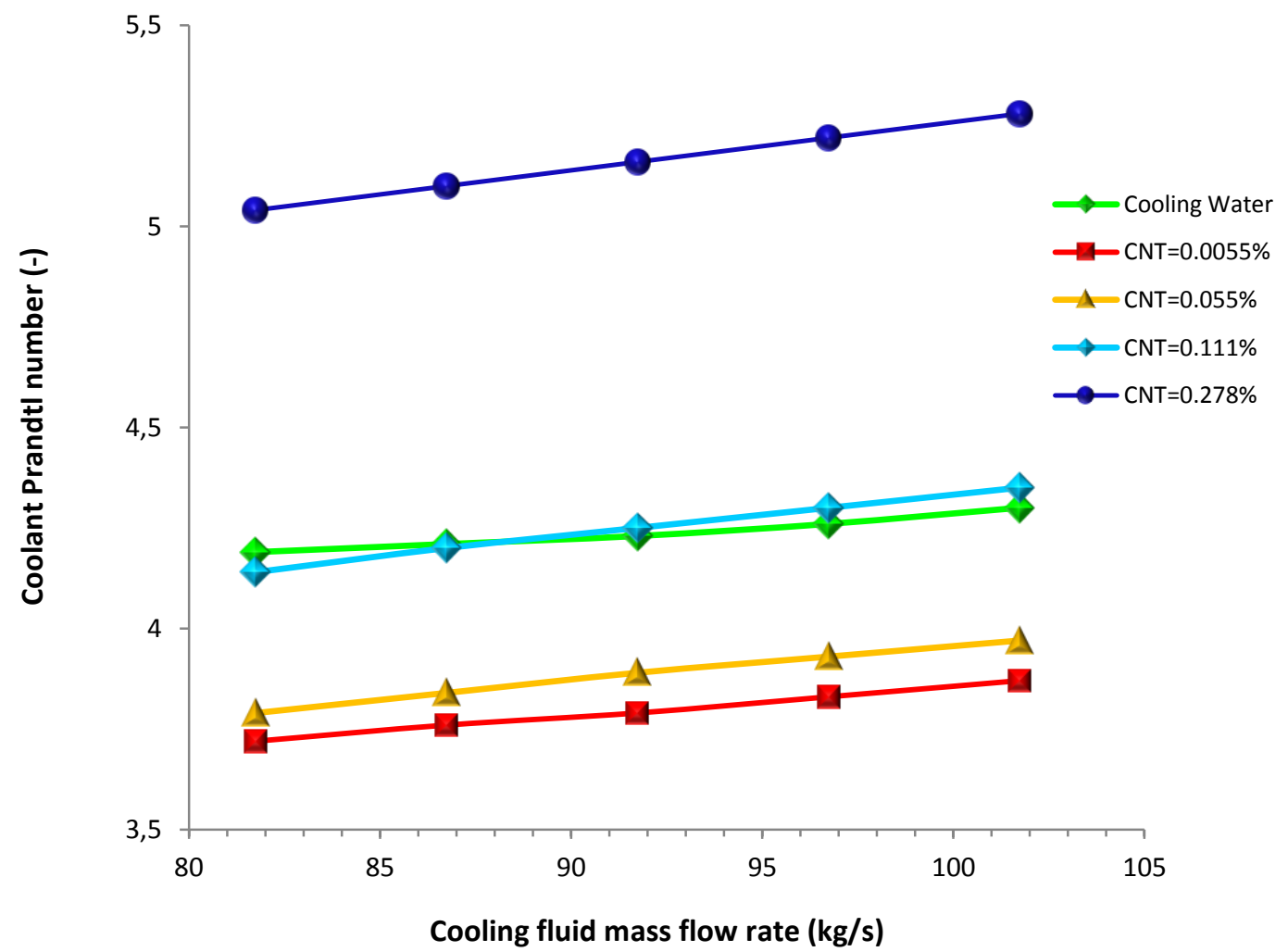

Fig. 13. Effect of $m_{n f}$ on Prandtl number 
It would be understood from Eq. 4 that friction factor has an inverse relation with Reynolds number as friction factor decreases with increase of Reynolds number due to the mass flow rate. This trend has been demonstrated in Figure 14. Figure 15 shows that the variations of the items mentioned above due to rise of the coolant mass flow rate result in the increase of Nusselt number. In other words, the rise of coolant mass flow rate causes increment of the Nusselt number for a constant CNT concentration. As can be seen, $\phi=0.055 \%$ possesses the highest Nusselt number.

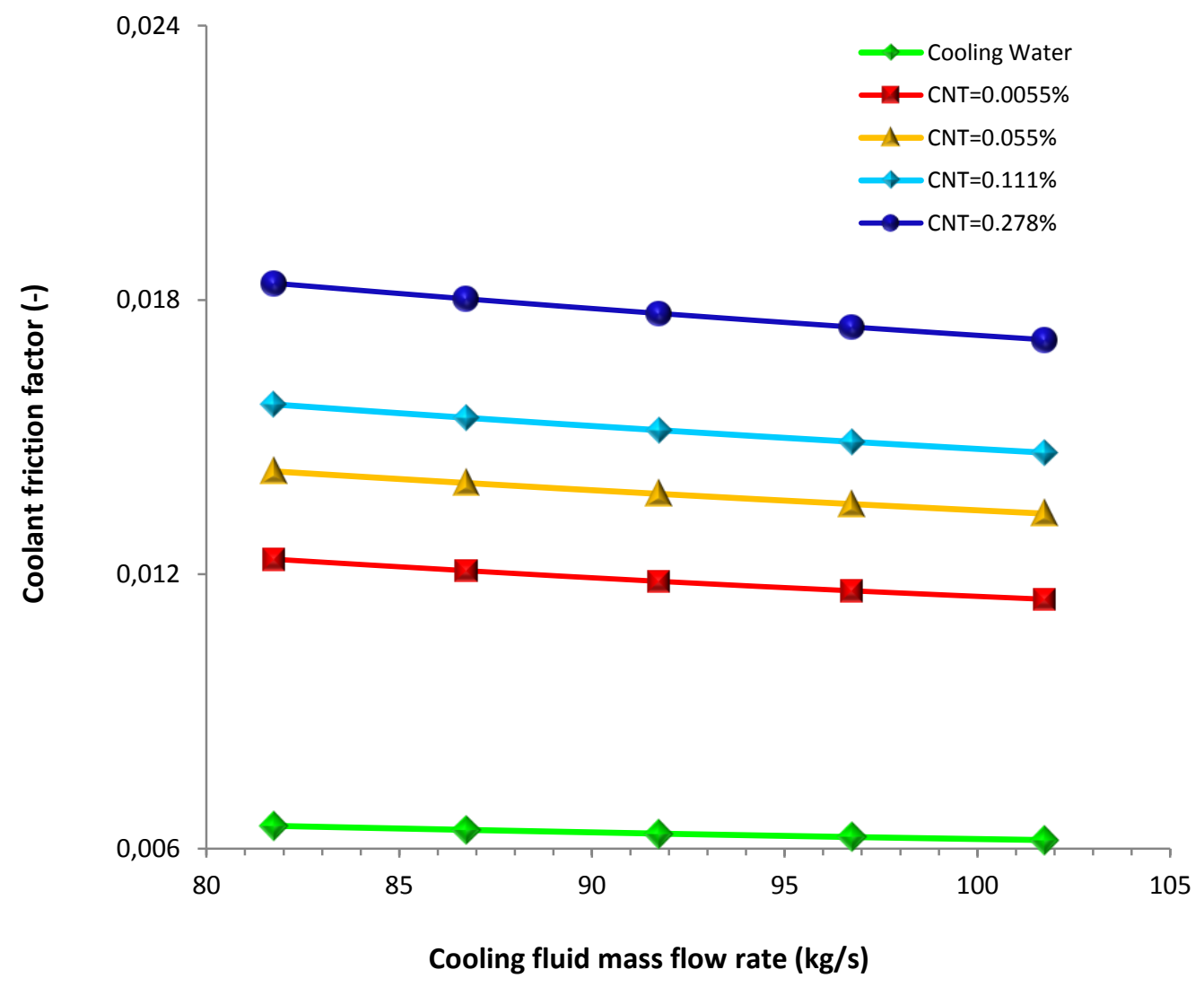

Fig. 14. Effect of $m_{n f}$ on the friction factor 


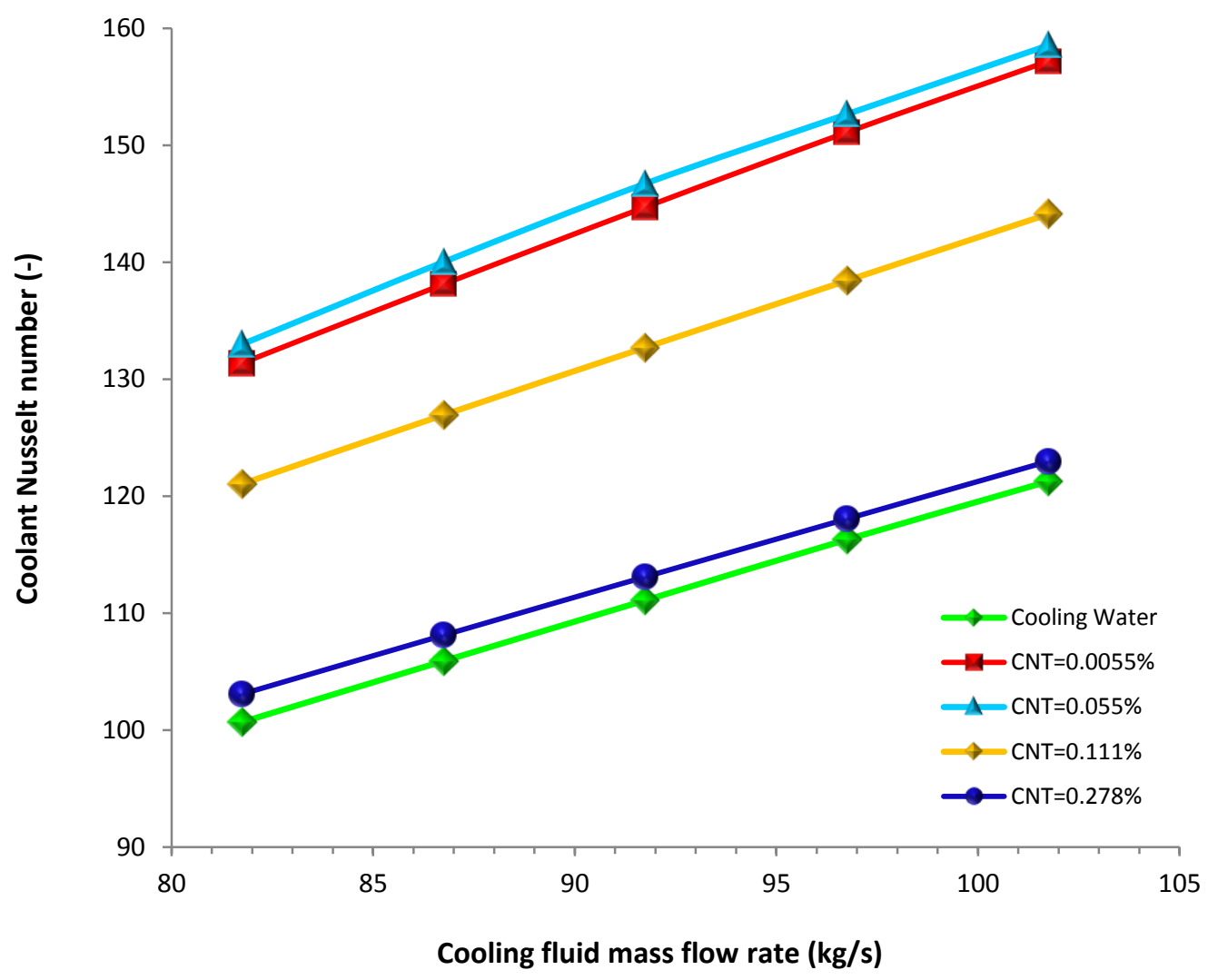

Fig. 15. Effect of $m_{n f}$ on the Nusselt number

It is clear from Fig. 16 that as the coolant mass flow rate increases, tube side pressure drop increase, too as well as it increases with $\phi$. Regarding Eqs. (6-8), the Nusselt number increase makes the total heat transfer coefficient increase (Fig. 17) for all the concentrations. With increase of the total heat transfer coefficient, finally, rise of heat transfer rate happens (Fig. 18), in particular, for $\phi=0.055 \%$ since this loading amount has the maximum total heat transfer coefficient and Nusselt number.

As the heat transfer from the shell side fluid to the tube side cold one, with increase of the heat transfer due to mass flow rate, the outlet temperature of the shell side fluid decreases as it is evidenced in Fig. 19. Reasonably, minimum outlet temperature belongs to $0.055 \%$ CNT loading since the heat exchanger has highest heat transfer rate with this cooling nanofluid. 


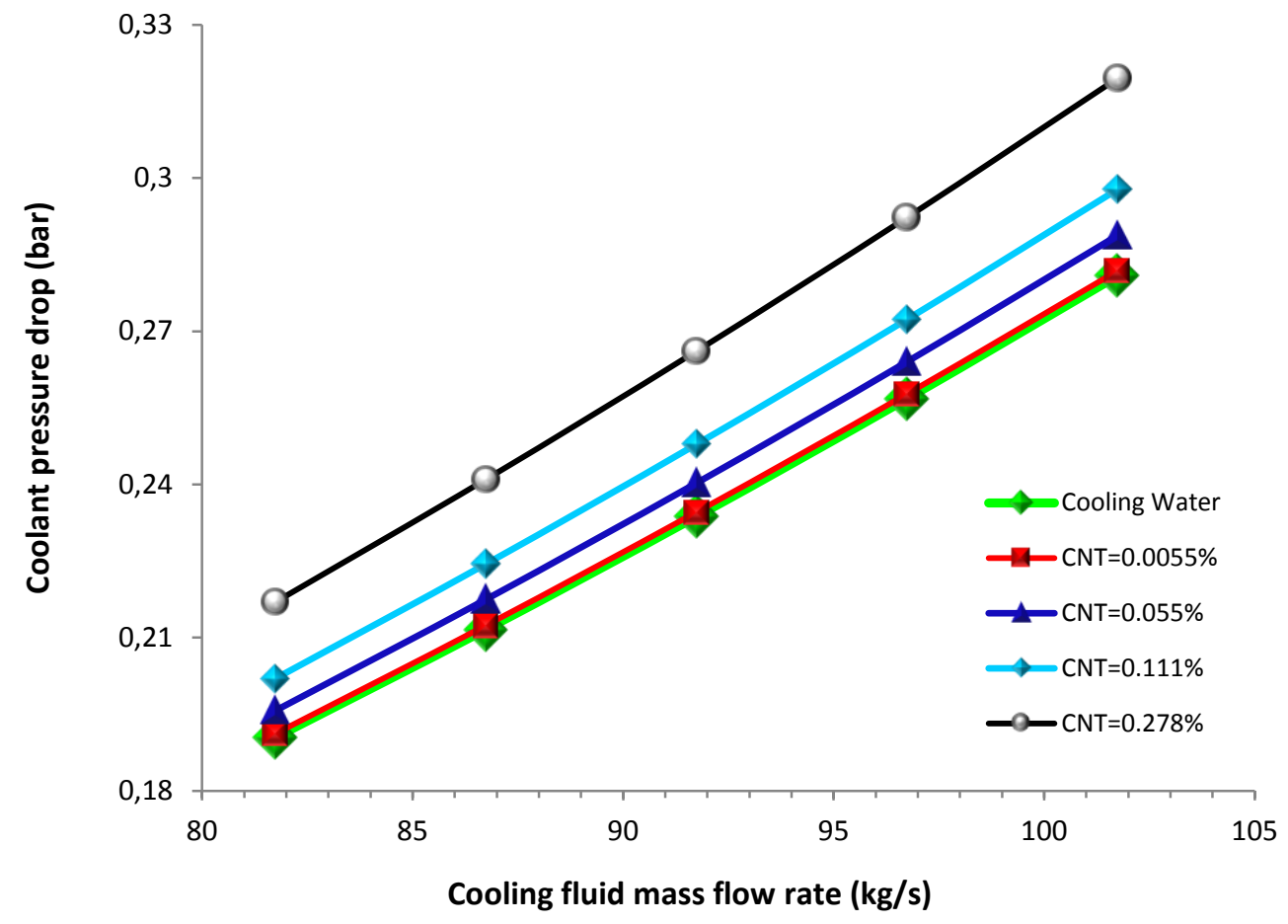

Fig. 16. Coolant pressure drop as a function of $m_{n f}$

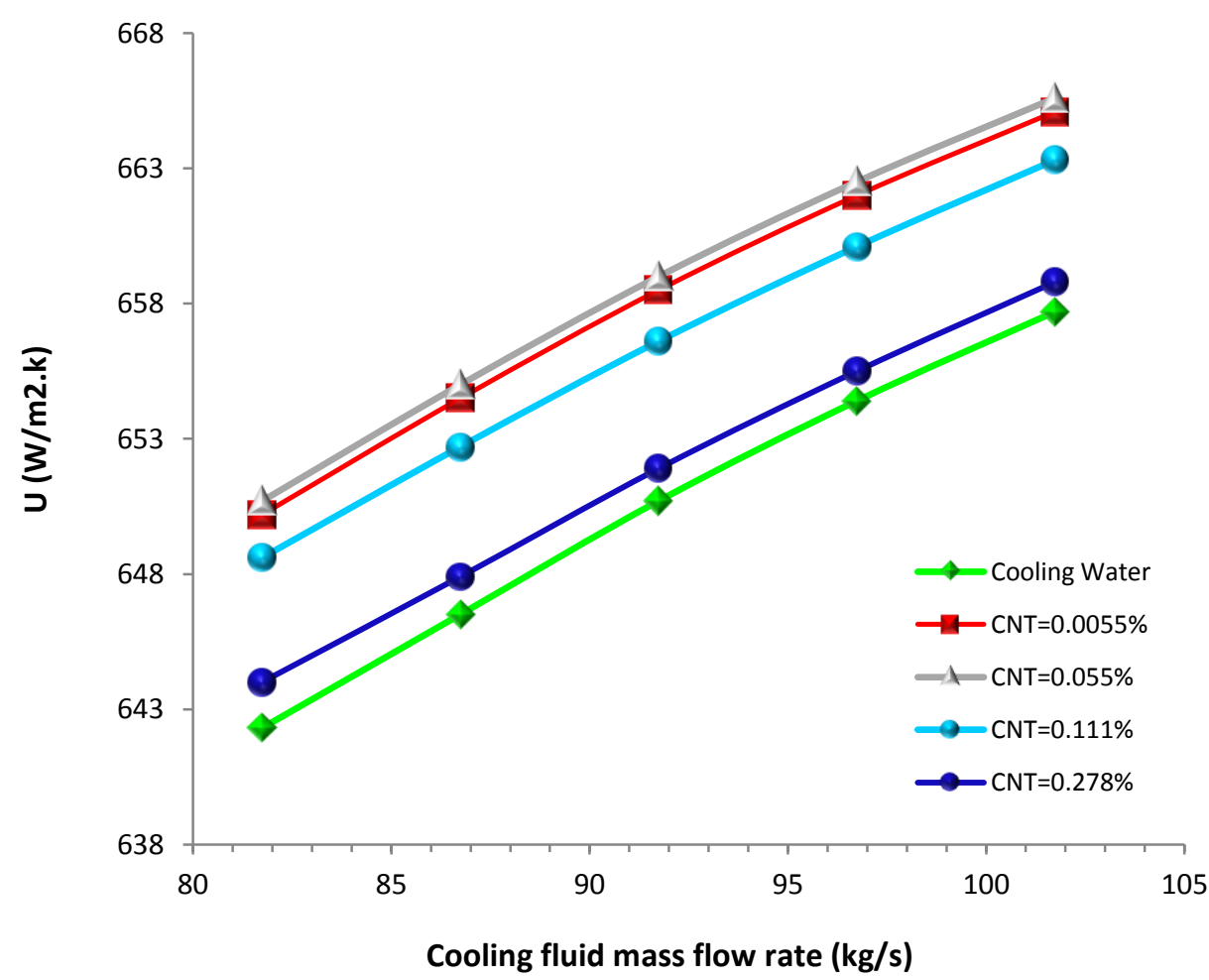

Fig. 17. Effect of $m_{n f}$ on total heat transfer coefficient 


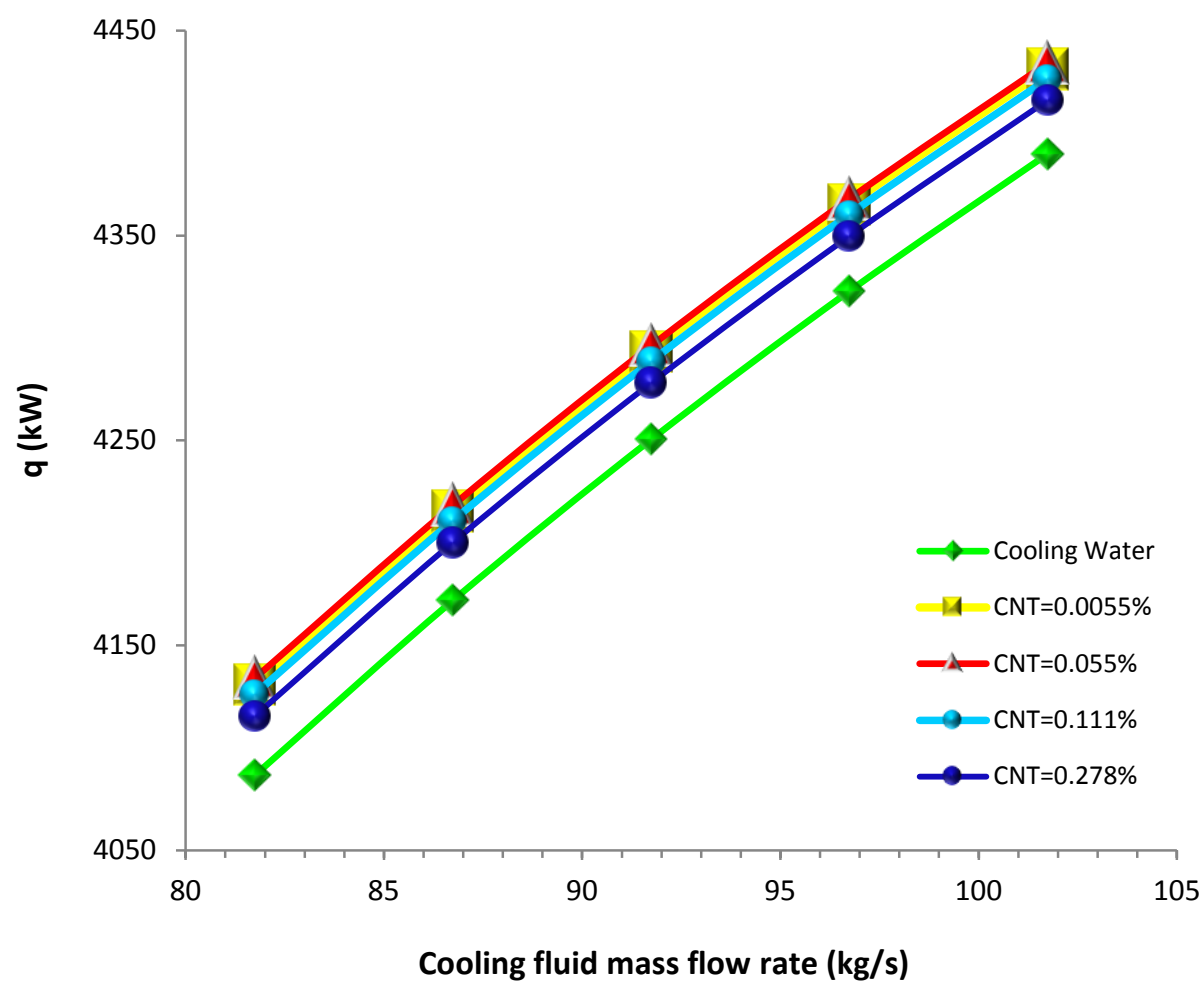

Fig. 18. Effect of $m_{n f}$ on heat transfer rate

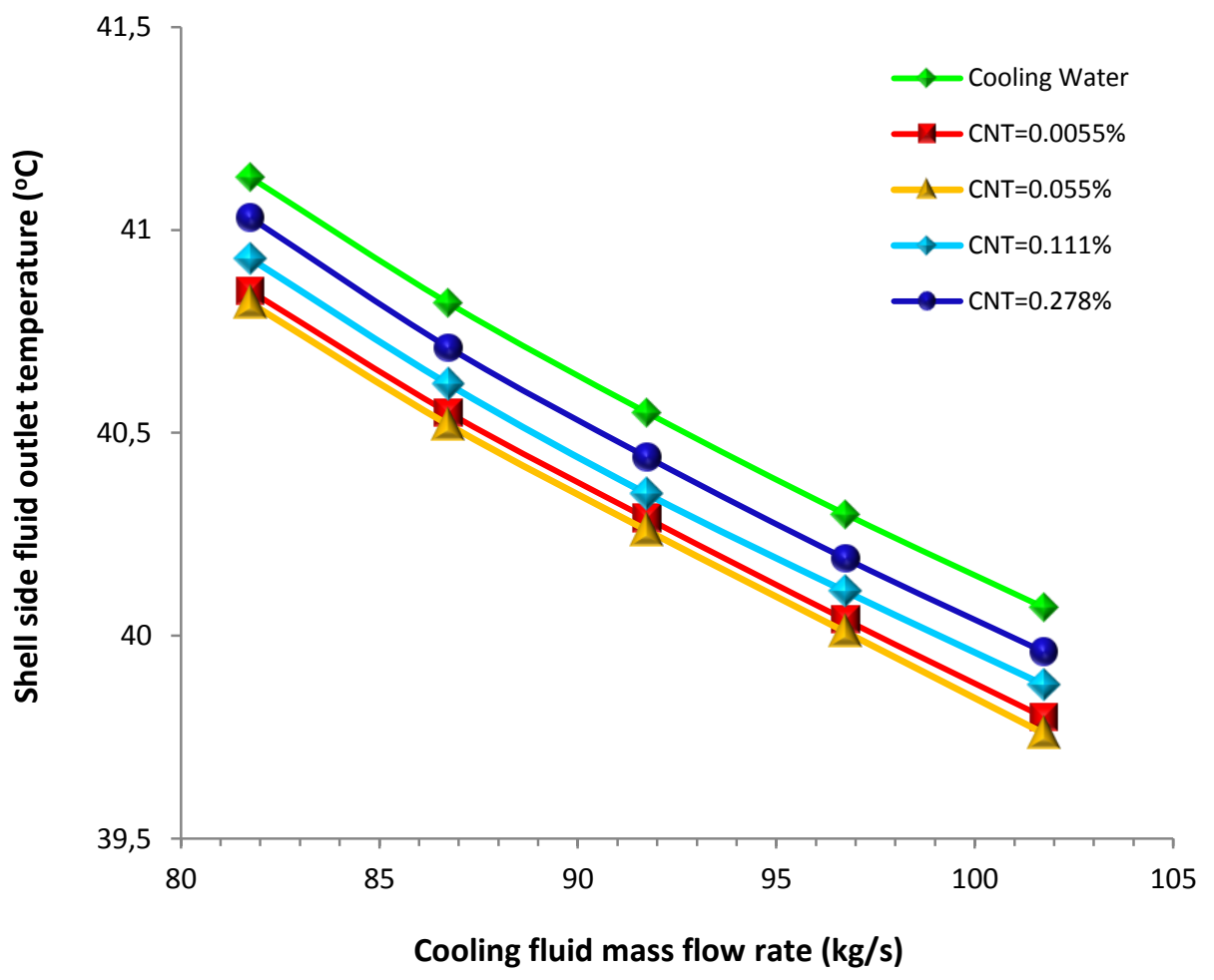

Fig. 19. The shell side fluid Outlet temperature versus the $m_{n f}$ 
4.3. Effect of shell side fluid (the gasoline) mass flow rate on thermal performance using CNT-water nanofluid as coolant

Figure 20 shows that the Re of the shell side increases by increasing the mass flow rate $\dot{m}$ based on Eq. (9).

$$
R e_{s S}=\left(\frac{m_{s S}}{A_{c f}}\right) \frac{D_{e}}{\mu_{s S}}
$$

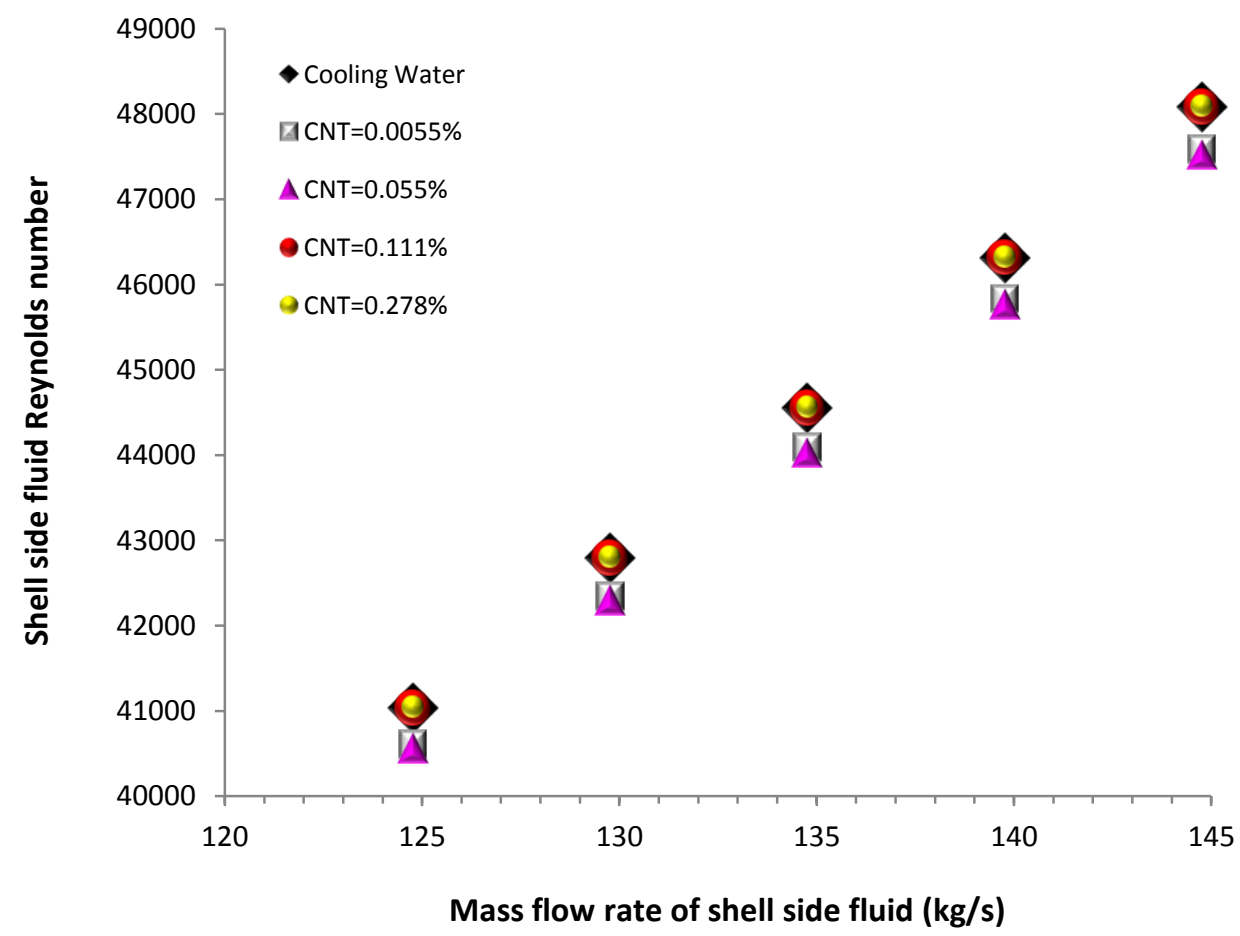

Fig. 20. Reynolds number of shell side fluid as a function of $m_{s S}$

Eq. (10) [24] shows that higher Re results in higher convection heat transfer coefficient, and consequently, higher heat transfer rate (Eqs. 7 and 8). As shown in Figures 21 and 22, increasing of shell side mass flow rate results in higher total heat transfer coefficient and heat transfer rate. Nanofluid coolant results in better thermal performance compared to pure water coolant.

$h_{S S}=\frac{0.36 k}{D_{e}} \operatorname{Re}_{S S}^{0.55} \operatorname{Pr}_{s S}^{\frac{1}{3}}$ 


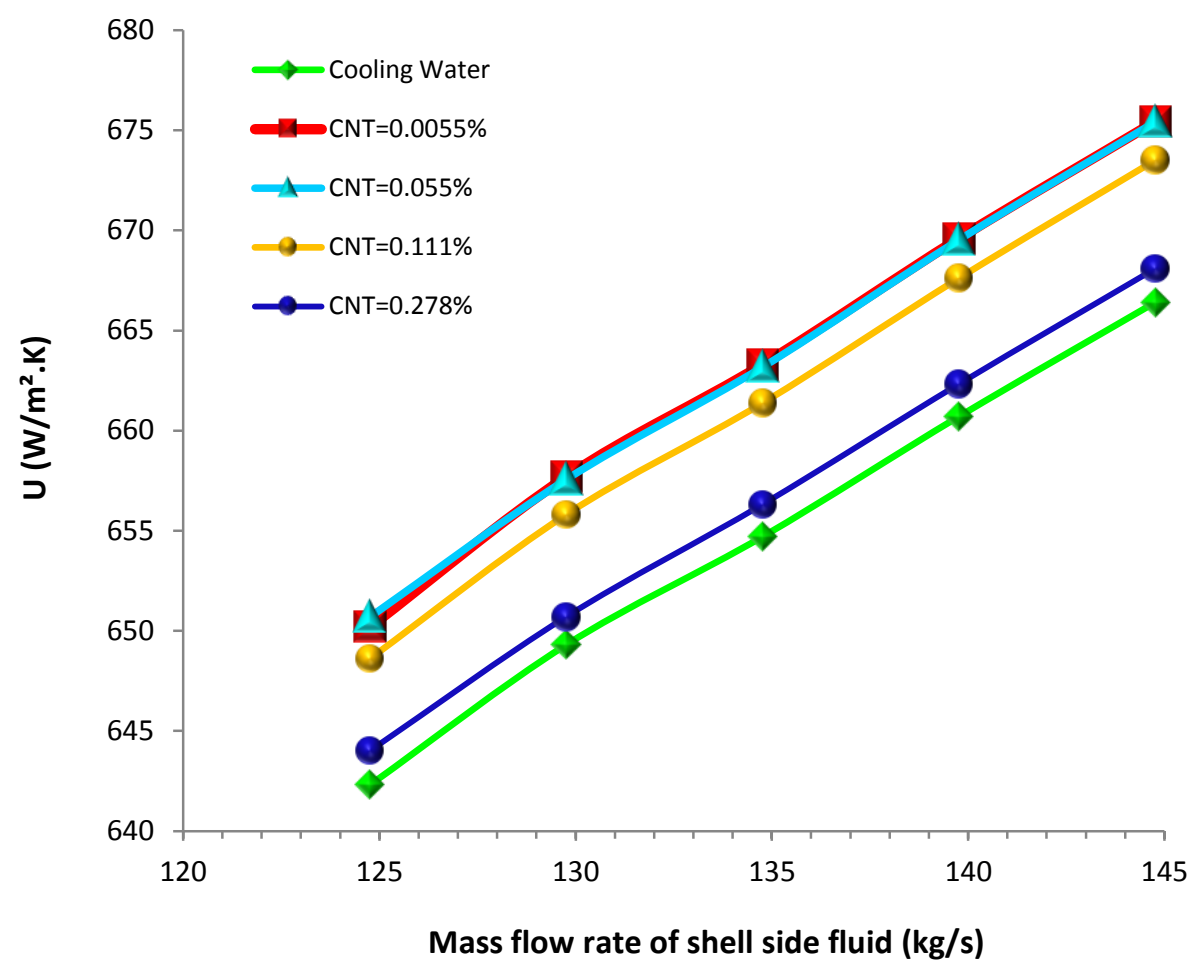

Fig. 21. Total heat transfer coefficient versus $m_{s s}$

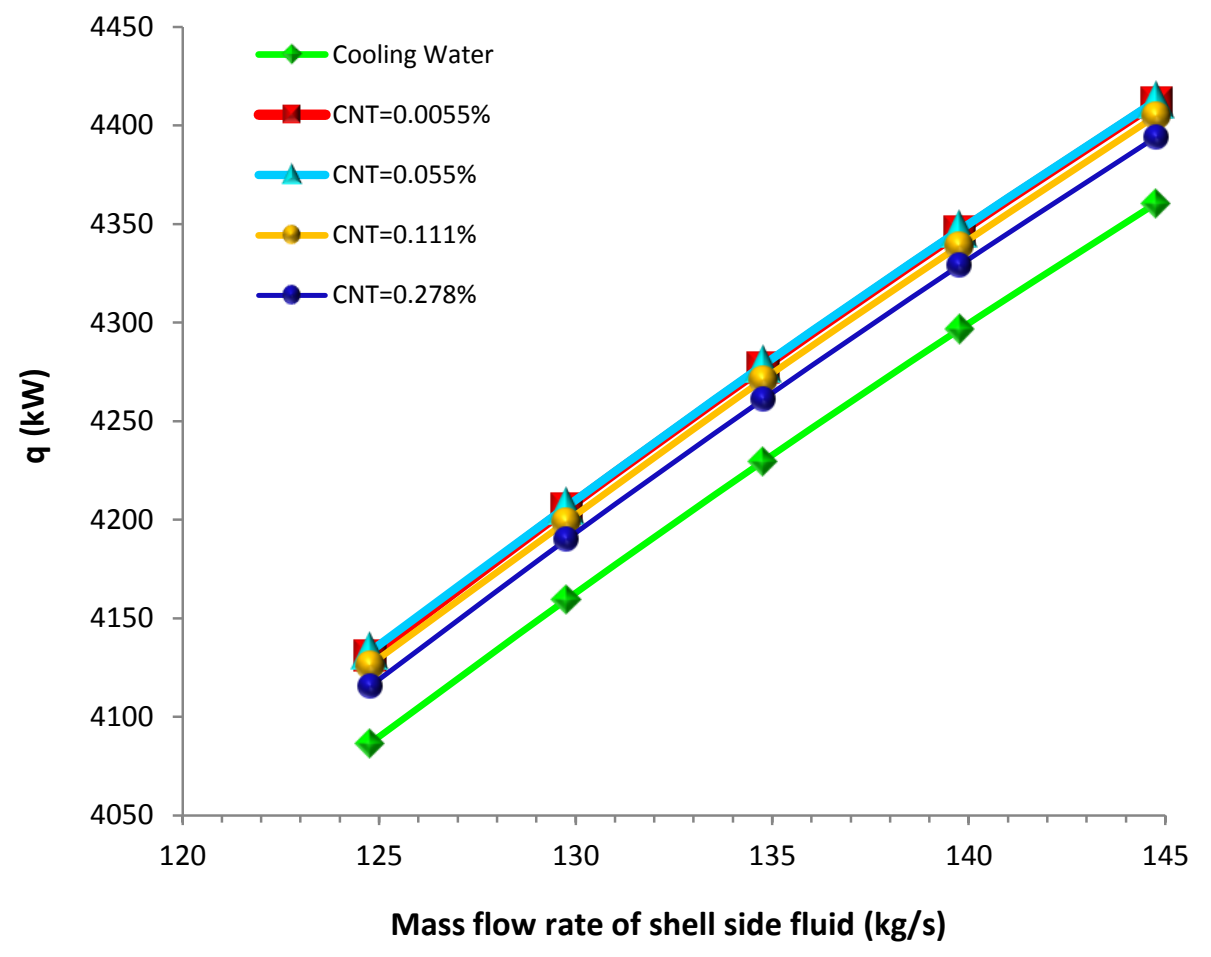

Fig. 22. Heat transfer rate versus $m_{s s}$ 
Figure 23 represents that with increasing mass flow rate of the hot fluid in shell side, outlet temperature of the shell side would also be increased. But, by comparing the nanofluid as coolant with cooling water, clearly, it can be observed that with a constant mass flow rate of shell side fluid, the hot fluid outlet temperature is clearly lower when nanofluid is utilized as coolant.

In other words, by using the nanofluid, shell side hot fluid is less heated related to using cooling water. Thus, by utilizing the nanofluid, viscosity of the shell side fluid would be higher than cooling water. Therefore, by using the nanofluid, Reynolds number of the shell side fluid decreases as expressed by Eq. 9. For instance, in Figure 20, the shell side fluid Reynolds reduces when water is replaced by nanofluids especially at $\phi=0.0055$ and $0.055 \%$. As demonstrated by Figure 23, the magnitude of the outlet temperature increase for $\phi=0.055$ is lower than for other concentrations since it causes most heat transfer rate.

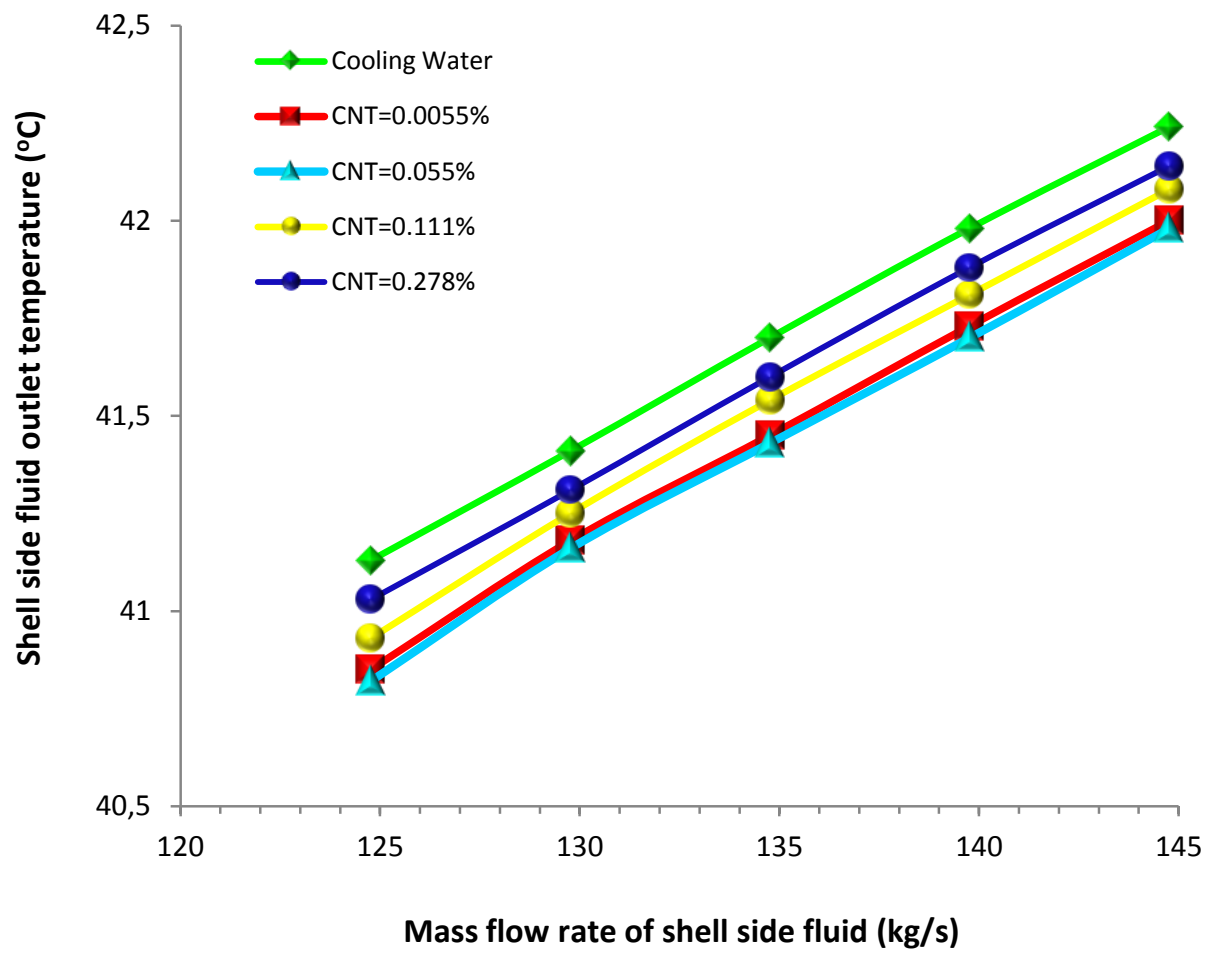

Fig. 23. Effect of $m_{s s}$ on its Outlet temperature 


\section{Conclusion}

This research studied the heat performance of an industrial scale shell and tube heat exchanger through software simulation by using CNT-water nanofluids as cooling fluids. Results illustrated that all analyzed CNT concentrations improved the heat properties such as Nusselt number, total heat transfer coefficient and heat transfer rate and, consequently they enhanced the heat performance of the heat exchanger. This enhancement was also effective to decrease outlet temperature of the shell side hot fluid for all CNT volume concentrations. Likewise, there was an optimum CNT concentration corresponding to $0.055 \mathrm{vol} \%$ of nanoparticles for which the heat properties reached maximum value and thermal performance of the heat exchanger is optimized. The heat performance enhancement was reached also by increasing mass flow rates of both the cooling nanofluid in all concentrations and the hot fluid in comparison with cooling water. It is also mentioned that optimum concentration of $0.055 \%$ also kept the best influence on thermal performance of the heat exchanger with increasing mass flow rates of the fluids in both sides.

\section{References}

[1] Ahmet Ozsoy, Vahit Corumlu, Thermal performance of a thermosyphon heat pipe evacuated tube solar collector using silver-water nanofluid for commercial applications, Renewable Energy, 122 (2018) 26-34.

[2] M. E. Nakhchi, J. A. Esfahani, Cu-water nanofluid flow and heat transfer in a heat exchanger tube equipped with cross-cut twisted tape, Powder Technology, 339 (2018) 985-994.

[3] N. Budak Ziyadanogullari, H.L.Yucel, C.Yildiz, Thermal performance enhancement of flat-plate solar collectors by means of three different nanofluids, Thermal Science and Engineering Progress, 8 (2018) 55-65.

[4] Sedong Kim, Baasandulam Tserengombo, Soon-HoChoi, Jungpil Noh, Sunchul Huh, Byeongkeun Choi, Hanshik Chung, Junhyo Kim, Hyomin Jeong, Experimental investigation of heat transfer coefficient with $\mathrm{Al}_{2} \mathrm{O}_{3}$ nanofluid in small diameter tubes, Applied Thermal Engineering, 146 (2019) 346-355.

[5] Nor Azwadi Che Sidik, Muhammad Noor Afiq Witri Muhammad Yazid, Syahrullail Samion, A review on the use of carbon nanotubes nanofluid for energy harvesting system, International Journal of Heat and Mass Transfer,111 (2017) 782-794.

[6] Yanwei Hu, Haoran Li, Yurong He, Ziyu Liu, Yunhua Zhao, Effect of nanoparticle size and concentration on boiling performance of $\mathrm{SiO}_{2}$ nanofluid, International Journal of Heat and Mass Transfer, 107(2017) 820-828. 
[7] R.M. Sarviya, Veeresh Fuskele, Review on Thermal Conductivity of Nanofluids, Materials Today Proceedings, 4 (2017) 4022-4031.

[8] Mehdi Bahiraei, Reza Rahmani, Ali Yaghoobi, Erfan Khodabandeh, Ramin Mashayekhi, Mohammad Amani, Recent research contributions concerning use of nanofluids in heat exchangers: A critical review, Applied Thermal Engineering, 133, 25 (2018) 137-159.

[9] Vikas Kumar, Arun Kumar Tiwari, Subrata Kumar Ghosh, Application of nanofluids in plate heat exchanger: A review, Energy Conversion and Management, 105 (2015) 1017-1036.

[10] Valtteri Mikkola, Salla Puupponen, Kari Saari, Tapio Ala-Nissila, Ari Seppälä, Thermal properties and convective heat transfer of phase changing paraffin nanofluids, International Journal of Thermal Sciences, 117 (2017) 163-171.

[11] Elisa Sani, Nicolò Papi, Luca Mercatelli, Gaweł Żyła, Graphite/diamond ethylene glycolnanofluids for solar energy applications, Renewable Energy, 126 (2018) 692-698.

[12] Saman Rashidi, Mohammad Hossein Kashefi, Kyung Chun Kim, Omid Samimi-Abianeh, Potentials of porous materials for energy management in heat exchangers -A comprehensive review, Applied Energy, 243 (2019) 206-232.

[13] Hamid Shamsabadi, Saman Rashidi, Javad Abolfazli Esfahani, Entropy generation analysis for nanofluid flow inside a duct equipped with porous baffles, Thermal Analysis and Calorimetry, 2018, DOI: 10.1007/s10973-018-7350-4.

[14] Saman Rashidi, Parniyan Javadi, Javad Abolfazli Esfahani, Second law of thermodynamics analysis for nanofluid turbulent flow inside a solar heater with the ribbed absorber plate, Thermal Analysis and Calorimetry, 2018, DOI: 10.1007/s10973-018-7164-4.

[15] S. Rashidi, M. Akbarzadeh, N. Karimi, R. Masoodi, Combined effects of nanofluid and transverse twisted-baffles on the flow structures, heat transfer and irreversibilities inside a square duct-A numerical study, Applied Thermal Engineering, 130 (2018) 135-148.

[16] R. Parizad Laein, S. Rashidi, J. Abolfazli Esfahani, Experimental investigation of nanofluid free convection over the vertical and horizontal flat plates with uniform heat flux by PIV, Advanced Powder Technology, 27 (2016) 312-322.

[17] Mahla Maskaniyan, Saman Rashidi, Javad Abolfazli Esfahani, A two-way couple of EulerianLagrangian model for particle transport with different sizes in an obstructed channel, Powder Technology, 312 (2017) 260-269.

[18] Saman Rashidi, Omid Mahian, Ehsan Mohseni Languri, Applications of nanofluids in condensing and evaporating systems A review, Thermal Analysis and Calorimetry, 2017, DOI: 10.1007/s10973-017-6773-7. 
[19] S. Rashidi, M. Eskandarian, O. Mahian, S. Poncet, Combination of nanofluid and inserts for heat transfer enhancement, Thermal Analysis and Calorimetry, 2018, DOI: 10.1007/s10973-0187070-9.

[20] Omid Mahian, Lioua Kolsi, Mohammad Amani, Patrice Estellé, Goodarz Ahmadi, ClementKleinstreuer, Jeffrey S. Marshall, Robert A. Taylor, Hamid Niazmand, Somchai Wongwises, Tasawar Hayat, Arun Kolanjiyil, Alibakhsh Kasaeian, Ioan Pop, Recent advances in modeling and simulation of nanofluid flows-Part I: Fundamentals and theory, Physics Reports, 790 (2019) 1-48.

[21] Saman Rashidi, Faramarz Hormozi, Bengt Sundenc, Omid Mahian, Energy saving in thermal energy systems using dimpled surface technology -A review on mechanisms and applications, Applied Energy 250 (2019) 1491-1547.

[22] Ramtin Barzegariana, Alireza Aloueyanb, Tooraj Yousefic, Thermal performance augmentation using water based $\mathrm{Al}_{2} \mathrm{O}_{3}$-gamma nanofluid in a horizontal shell and tube heat exchanger under forced circulation, International Communications in Heat and Mass Transfer, 86 (2017) 52- 59.

[23] I.M. Shahrul, I.M. Mahbubul, R. Saidur, M.F.M. Sabri, Experimental investigation on $\mathrm{Al}_{2} \mathrm{O}_{3}-\mathrm{W}$, $\mathrm{SiO}_{2}-\mathrm{W}$ and $\mathrm{ZnO}-\mathrm{W}$ nanofluids and their application in a shell and tube heat exchanger, International Journal of Heat and Mass Transfer, 97 (2016) 547-558.

[24] S. Masoud Hosseini, Leila Vafajoo, B.H. Salman, Performance of CNT-water nanofluid as coolant fluid in shell and tube intercooler of a LPG absorber tower, International Journal of Heat and Mass Transfer, 102 (2016) 45-53.

[25] Ghanem Al-Abdali, Hussein M. Maghrabie, M. Attalla, Investigation of heat transfer and friction factor of $\mathrm{Al}_{2} \mathrm{O}_{3}$ nanofluid inside shell and tube heat exchanger, Scientific and Engineering Research, 5 (2018) 549-556.

[26] Mohammad Hossein Aghabozorg, Alimorad Rashidi, Saber Mohammadi, Experimental investigation of heat transfer enhancement of $\mathrm{Fe}_{2} \mathrm{O}_{3}-\mathrm{CNT} /$ water magnetic nanofluids under laminar, transient and turbulent flow inside a horizontal shell and tube heat exchanger, Experimental Thermal and Fluid Science, 72 (2016) 182-189.

[27] Omid Mahian, Lioua Kolsi, Mohammad Amani, Patrice Estellé, GoodarzAhmadi, ClementKleinstreuer, Jeffrey S. Marshall, Robert A. Taylor, Hamid Niazmand, Somchai Wongwises, Tasawar Hayat, Arun Kolanjiyil, Alibakhsh Kasaeian, Ioan Pop, Recent advances in modeling and simulation of nanofluid flows-Part II: Applications, Physics Reports, 791 (2019) 1-59.

[28] P. Estellé, O. Mahian, T. Maré, H. F. Öztop, Natural convection of CNT water based nanofluids in a differentially heated square cavity, Journal of Thermal Analysis and Calorimetry 128(3) (2017) $1765-1770$

[29] A.A. Minea, P. Estellé, Numerical study on CNT nanofluids behavior in laminar pipe flow, Journal of Molecular Liquids 271 (2018) 281-289.

[30] N. Mohd-Ghazali, P. Estellé, S. Halelfadl, T. Maré, T. Choon Sionga, U. Abidin, Thermal and hydrodynamic performance of a microchannel heat sink with carbon nanotubes nanofluids: Effect of concentration and channel section, Journal of Thermal Analysis and Calorimetry (2019) DOI: 10.1007/s10973-019-08260-2, available on line 
[31] Salma Halelfadl, Thierry Mare, Patrice Estellé, Efficiency of carbon nanotubes water based nanofuids as coolants, Experimental Thermal and Fluid Science, 53 (2014) 104-110.

[32] www.korenergy.co.kr

[33] V. Gnielinski, New equations for heat and mass transfer in turbulent pipe and channel flow, International Chemical Engineering, 16 (1976) 359-368.

[34] W. Duangthongsuk, S. Wongwises, Heat transfer enhancement and pressure drop characteristics of $\mathrm{TiO}_{2}$-water nanofluid in a double-tube counter flow heat exchanger. International Journal of Heat and Mass Transfer, 52 (2009) 2059-2067. 